\title{
Modelling, Design and Analysis of Low Frequency Platform \\ for Attenuating Micro-Vibration in Spacecraft
}

\author{
D. Kamesh ${ }^{\dagger}$ R. Pandiyan ${ }^{\dagger}$, Ashitava Ghosal ${ }^{*}$ \\ $\dagger$ ISRO Satellite Centre, Bangalore, INDIA * Indian Institute of Science, Bangalore, INDIA
}

\begin{abstract}
One of the most important factors that affect the pointing of precision payloads and devices in space platforms is the vibration generated due to static and dynamic unbalanced forces of rotary equipments placed in the neighborhood of payload. Generally, such disturbances are of low amplitude, less than $1 \mathrm{kHz}$, and are termed as 'micro-vibrations'. Due to low damping in the space structure, these vibrations have long decay time and they degrade the performance of payload. This paper addresses the design, modeling and analysis of a low frequency space frame platform for passive and active attenuation of micro-vibrations. This flexible platform has been designed to act as a mount for devices like reaction wheels, and consists of four folded continuous beams arranged in three dimensions. Frequency and response analysis have been carried out by varying the number of folds, and thickness of vertical beam. Results show that lower frequencies can be achieved by increasing the number of folds and by decreasing the thickness of the blade. In addition, active vibration control is studied by incorporating piezoelectric actuators and sensors in the dynamic model. It is shown using simulation that a control strategy using optimal control is effective for vibration suppression under a wide variety of loading conditions.
\end{abstract}

\section{Introduction}

Vibration propagation into mechanical systems can cause many problems at different levels resulting in performance degradation of sensitive systems [1]. Vibrations

\footnotetext{
${ }^{\dagger}$ Corresponding author.

E-mail address: kamesh@isac.gov.in
} 
that occur at frequencies up to $1 \mathrm{kHz}$ have often been neglected in the past due to the low levels of disturbances. However, recently these have become very important and have received a great deal of attention by many researchers. This is especially true for spacecraft structures where, due to the ever increasing requirements to protect sensitive payloads, such as optical instruments or microgravity experiments, there is a pressing need for such micro-vibration suppression. In a spacecraft, micro-vibrations are produced by the functioning of on-board equipment such as reaction wheels, gyroscopes, thrusters, electric motors, cryo-coolers and data storage devices. They propagate through the satellite structure towards sensitive payloads such as mid-wave infrared surveillance sensors, laser communication devices and astronomical telescopes thereby jeopardizing their correct functioning. Spacecraft that use control moment gyroscopes (CMG) for attitude control tend to have high sensitivity to pointing and jitter, creating a need for isolation [2]. Passive vibration suppression and isolation is the recommended first approach, to try to reduce these unwanted disturbances $[3,4,5,6]$. From a practical standpoint, the reduction of the vibration level at a sensitive location of a structure can be attempted by placing the equipment on appropriate mountings [7, 8]. The Hubble Space Telescope (HST) is probably the best known example of a spacecraft that includes an isolation system that is necessary to achieve its science mission [9] - it uses a passive isolation system to mitigate effects from the reaction wheel assembly that points the spacecraft. The system, designed by Honeywell, employs a viscous fluid-damped isolator. Another example of an isolator used in several space missions is the Honeywell D-Strut [10] that uses a bellows system with a viscous damped-fluid and is similar to the Hubble system. This isolator has been reengineered in recent years to combine a passive and active system. Vibration isolation has been tested with an Ultra Quite Platform (UQP) - a six axis Stewart platform active isolation system [11]. A high performance strut isolator has been developed for multi-axis isolation for reaction wheel assembly [12]. In this case a three parameter system with spring elements in series and parallel with the damper have been incorporated for each strut elements. The shape memory alloy (SMA) actuators have been used in [13], but its response time is too slow for vibration suppression using the thermal control to effect changes in 10 to $50 \mathrm{~Hz}$ range. An experimental investigation of shape memory alloy springs for passive vibration isolation 
has also been studied in [14]. All of the above passive isolation systems use a variety of implementation devices including visco-elastic materials, springs, soft materials, and hydraulic dampers, pneumatic isolator [15].

Passive damping limits the amplification at resonance but tends to reduce the high frequency attenuation of the isolation system. For demanding missions, passive solutions may have limited effectiveness, particularly if the disturbances are harmonic in nature and with broad frequency content such as those generated by cryo-cooler and reaction wheels. Active isolation has been introduced to resolve this conflict, allowing to achieve, simultaneously, a low amplification at resonance and a large attenuation at high frequency. Active six degree of freedom local vibration isolation applied to a flexible space telescope has been studied by Kaplow and Velman [16] for attenuating high frequency disturbances. Active vibration isolation interface to protect the spacecraft pointing accuracy from payload disturbances has been discussed in [17, 18, 19]. The piezoelectric Stewart platform for general purpose active damping has been studied in [17]. This uses stiff active damping interface as a support for payloads and it consists of a six degree of freedom Stewart platform, where each leg of the active interface is made of a linear piezoelectric actuator. Another six-axis single-stage active vibration isolator based on Stewart platform has been developed for space application [18]. The structural vibration control using an active resonator absorber (ARA) has been studied with PZT inertial actuators [19]. An integrated active damping device (IADD- a piezo based device) and the Multi-purpose Active Isolation System (MAIS) with a six DOF isolator based on six active struts (co-located piezo sensor \& actuator) arranged in hexapod configuration have been studied for high pointing accuracy satellites [20]. Active vibration control is also increasingly being used for flexible structures. In such control systems, the piezoelectric materials is embedded in the structural elements as actuators and these smart structures have advantages such as high stiffness, light weight, low cost, low power consumption and easy implementation. Crawley and Javier [21] have derived the static and dynamic models for segmented piezoelectric actuators bonded or embedded in the flexible structures. The use of surface mounted piezo-actuators as active dampers in reducing the free vibration decay time of cantilevered beams has been studied by 
Bailey and Hubbard [22]. Optimal control of vibration in flexible smart structures using piezo-sensors and actuators has been studied in [23, 24].

In this paper, a low frequency space platform has been proposed which can be used as a mounting device for payloads in spacecrafts for both passive and active control of disturbances arising due to micro-vibrations. Finite element analysis of the platform is carried out for static and dynamic load cases. Passive vibration control has been analyzed using modal analysis techniques to simulate the response of each mode for free and forced vibration cases. Active control has been studied by embedding the platform with piezo actuators and sensors. The simulation results show further improvement in vibration attenuation when active control is used.

This paper is organized as follows: In section 2, we present a detailed description of the space frame platform designed to suppress micro-vibrations. Section 3 describes the finite element formulation of the proposed platform. Results for different load cases described in section 4 show the effectiveness of the platform for passive control of vibration. Simulation results for active control are described in section 5. Concluding remarks on the performance of the designed isolator system are presented in section 6 .

\section{Description of flexible platform}

The study of isolator must be viewed as a system consisting of three parts - the source system in which the vibration is generated, the receiver system in which vibration force or response is felt and the interconnecting isolation system which connects the source to the receiver. The requirements of any isolator therefore will be to support the objects with sufficient static stiffness and strength and also to provide the smallest possible dynamic stiffness. Therefore, the isolator must support the equipment under static loading and must also be compliant so that disturbances are not transmitted to the precision equipments in spacecrafts. Design criteria [25] require that the low frequency platform support a generic payload up to $5.5 \mathrm{~kg}$ with a low isolation plunge frequency less than 15 Hz. Simulations were performed using Matlab [26] to determine the optimum geometry of the platform. The proposed low frequency space frame platform consisting of four folded beams is shown in Fig. 1. It comprises of four single folded beams placed orthogonal to each other. Each of these four folded beams is assembled on to the payload 
as shown in Fig. 2 which is considered to be a source of micro-vibrations. The other end of these beams is connected to a base platform of high stiffness whose first fundamental frequency is greater than $100 \mathrm{~Hz}$. The dimensions and properties of the flexible beams are given in Table 1. These dimensions have been arrived at by calculating the frequencies, displacements and reaction forces for varying geometric dimensions of the beam. The vertical beams are thinner than the horizontal beams, thus making them less stiff.

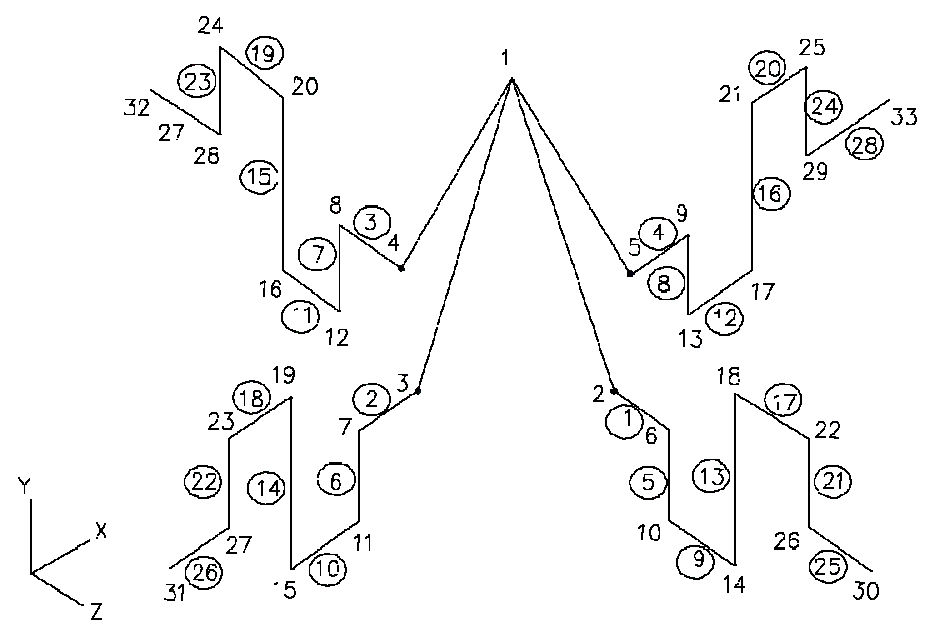

Figure 1 -- Flexible space frame platform. 


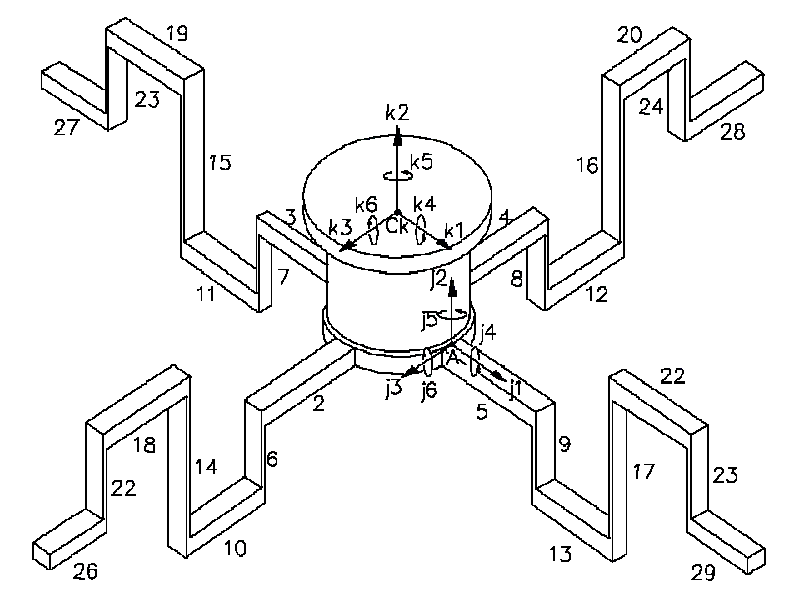

Figure 2 -- A rigid mass mounted on the flexible platform.

Table 1

Geometric, Mass and Physical properties of one fold beam.

Geometric properties

For elements 1, 2, 3, 4

Depth (m) 0.003

Length $(\mathrm{m}) \quad 0.035$

For elements 5, 6, 7, 8, 21, 22, 23, 24

Depth $(\mathrm{m}) \quad 0.001 /$ or $0.0008 /$ or 0.0006

Length (m) $\quad 0.024 /$ or $0.036 /$ or 0.048

\begin{tabular}{ll}
\hline $\begin{array}{l}\text { For elements } 9,10,11,12,17,18,19,20 \\
\text { Depth (m) } \\
\text { Length (m) }\end{array}$ & 0.003 \\
& 0.008 \\
\hline For elements 13, 14, 15, 16 & \\
Depth (m) & $0.001 /$ or $0.0008 /$ or 0.0006 \\
Length (m) & $0.048 /$ or $0.060 /$ or 0.072 \\
\hline For elements 25, 26, 27, 28 & \\
Depth (m) & 0.003 \\
Length (m) & 0.030 \\
\hline Width of all elements (m) & 0.025 \\
\hline Physical and Mass properties & \\
& \\
E, Modulus of elasticity & $21000 \mathrm{GPa}$ \\
G, Modulus of rigidity & $7000 \mathrm{GPa}$ \\
Density & $7800 \mathrm{~kg} / \mathrm{mm}^{3}$ \\
Mass of the object & $5.5 \mathrm{kgs}$ \\
Mass moment of inertia, $\mathrm{I}_{\mathrm{yy}}$ & $0.0465 \mathrm{~kg}-\mathrm{m}^{2}$ \\
Mass moment of inertia, $\mathrm{I}_{\mathrm{xx}} \& \mathrm{I}_{\mathrm{zz}}$ & $0.0270 \mathrm{~kg}-\mathrm{m}^{2}$ \\
\hline
\end{tabular}




\section{Finite Element Formulation}

Finite element analysis of the platform is carried out using frame elements with six degrees of freedom for each node. Flexure part of the frame element is modeled using the Euler-Bernoulli beam theory.

\subsection{Dynamic equation of motion of frame element}

For a typical element in the four folded beam shown in Fig. 3, the element degrees of freedom expressed in local axes Oxyz are [27]

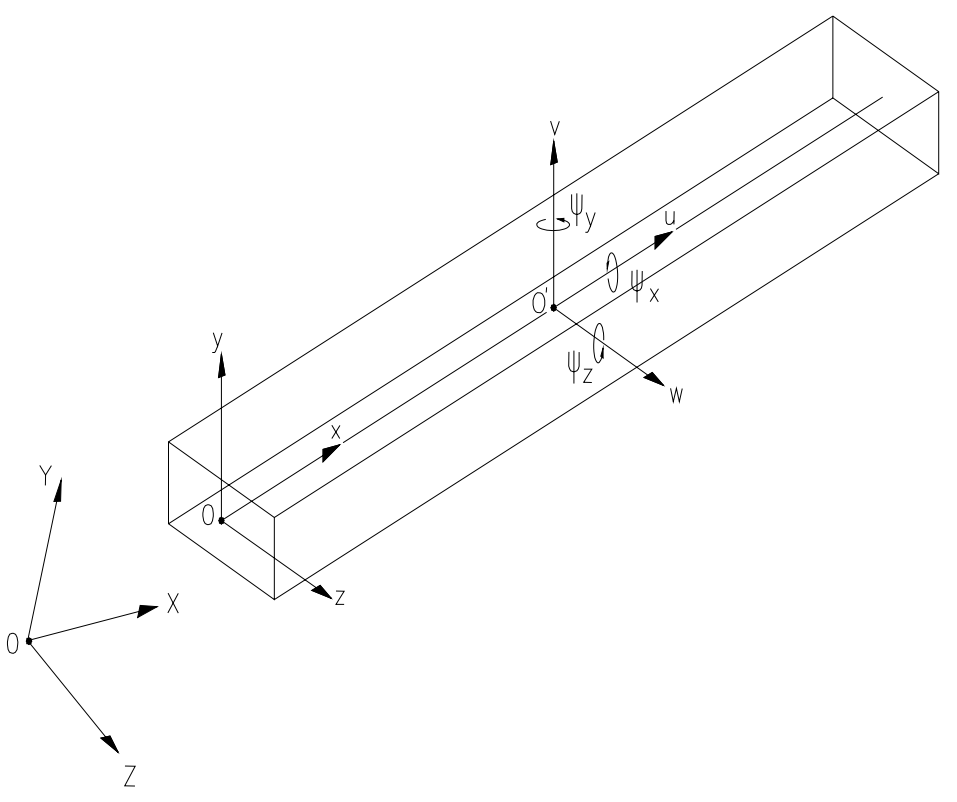

Figure 3 -- A typical beam element.

$$
\mathbf{q}_{\mathrm{eL}}^{\mathrm{T}}=\left[u_{1} v_{1} w_{1} \psi_{x 1} \psi_{y 1} \psi_{z 1} u_{2} v_{2} w_{2} \psi_{x 2} \psi_{y 2} \psi_{z 2}\right]
$$

and the rotation $\boldsymbol{\psi}_{\boldsymbol{x}}$ and $\boldsymbol{\psi}_{\boldsymbol{y}}$ are linked to deflection by

$$
\Psi_{\mathrm{x}}=\frac{\partial v}{\partial x}, \boldsymbol{\Psi}_{\mathrm{y}}=-\frac{\partial w}{\partial x}
$$

As the frame element consists of beam element, bar element and torsional element, the strain energy of the frame element with uniform cross section is obtained as the sum of 
energies of the above elements. The element $(12 \times 12)$ stiffness matrix $\mathbf{K}_{\mathrm{eL}}$ in local axes is composed of $(6 \times 6)$ sub-matrices and is of the form

$$
\mathbf{K}_{\mathrm{eL}}=\left[\begin{array}{cc}
\mathbf{K}_{j j} & \mathbf{K}_{j k} \\
\mathbf{K}_{k j} & \mathbf{K}_{k k}
\end{array}\right]
$$

with

$$
\mathbf{K}_{j k}=\mathbf{K}_{k j}
$$

The element mass matrix as described from the kinetic energy of the frame element is also composed of $(6 \times 6)$ sub-matrices and is of the form

$$
\mathbf{M}_{\mathrm{eL}}=\left[\begin{array}{ll}
\mathbf{M}_{j j} & \mathbf{M}_{j k} \\
\mathbf{M}_{k j} & \mathbf{M}_{k k}
\end{array}\right]
$$

with

$$
\mathbf{M}_{j k}=\mathbf{M}_{k j}
$$

The elementary stiffness and mass matrices are expressed in structural axes $O X Y Z$, by performing the rotation from local frame to structural frame using the operator $\mathbf{T}$

$$
\begin{gathered}
\mathbf{q}_{\mathrm{eL}}=\mathbf{T q}_{\mathrm{e} S} \\
\mathbf{K}_{\mathrm{eS}}=\mathbf{T}^{\mathrm{T}} \mathbf{K}_{\mathrm{eL}} \mathbf{T} \\
\mathbf{M}_{\mathrm{eS}}=\mathbf{T}^{\mathrm{T}} \mathbf{M}_{\mathrm{eL}} \mathbf{T}
\end{gathered}
$$

where $\mathbf{T}$ is a $12 \times 12$ block diagonal matrix with 4 blocks of $3 \times 3$ rotation matrix. The structural degrees of freedom for the element are

$$
\mathbf{q}_{\mathrm{eS}}^{\mathrm{T}}=\left\lfloor U_{1} v_{1} W_{1} \psi_{z 1} \psi_{Y 1} \psi_{z 1} U_{2} v_{2} w_{2} \psi_{z 2} \psi_{Y 2} \psi_{z 2}\right\rfloor
$$

The undamped equations of motion describing the nodal displacements of the attached and free nodes, devoid of contribution from the rigid body are given as [27]

$$
\left[\begin{array}{ll}
\mathbf{M}_{A A} & \mathbf{M}_{A F} \\
\mathbf{M}_{F A} & \mathbf{M}_{F F}
\end{array}\right]\left\{\begin{array}{l}
\ddot{\mathbf{D}}_{A} \\
\ddot{\mathbf{D}}_{F}
\end{array}\right\}+\left[\begin{array}{ll}
\mathbf{K}_{A A} & \mathbf{K}_{A F} \\
\mathbf{K}_{F A} & \mathbf{K}_{F F}
\end{array}\right]\left\{\begin{array}{l}
\mathbf{D}_{A} \\
\mathbf{D}_{F}
\end{array}\right\}=\left\{\begin{array}{l}
\mathbf{A}_{A}(t) \\
\mathbf{A}_{F}(t)
\end{array}\right\}
$$


To account for the presence of rigid body, we realize that nodes of type A (Fig. 2.) are constrained to move with the rigid body. Thus, the actions, stiffness, and mass are transformed from A to $\mathrm{C}$, the centre of mass of the rigid body as follows:

$$
\left[\begin{array}{l}
\mathbf{A}_{B} \\
\mathbf{A}_{F}
\end{array}\right]=\mathbf{Q}\left[\begin{array}{l}
\mathbf{A}_{A} \\
\mathbf{A}_{F}
\end{array}\right]
$$

For displacement and acceleration, we have

$$
\left[\begin{array}{l}
\mathbf{D}_{A} \\
\mathbf{D}_{F}
\end{array}\right]=\mathbf{Q}^{\mathrm{T}}\left[\begin{array}{l}
\mathbf{D}_{\bar{v}} \\
\mathbf{D}_{F}
\end{array}\right]
$$

and

$$
\left[\begin{array}{l}
\ddot{\mathbf{D}}_{A} \\
\ddot{\mathbf{D}}_{F}
\end{array}\right]=\mathbf{Q}^{\mathrm{T}}\left[\begin{array}{l}
\ddot{\mathbf{D}}_{B} \\
\dot{\mathbf{D}}_{F}
\end{array}\right]
$$

The transformation operator $\mathbf{Q}$ in Eqs. (8), (9), and (10) is given as,

$$
\mathbf{Q}=\left[\begin{array}{cc}
\mathbf{Q}_{B A} & 0 \\
0 & \mathbf{I}_{F}
\end{array}\right]
$$

in which $\mathbf{I}_{F}$ is the identity matrix of order equal to the number of free nodal displacements. The transformation matrix $\mathbf{Q}_{B A}$ is a sparse array containing the submatrices which transform actions, stiffness and consistent mass from node A to node C. Pre-multiplying Eq. (7) by $\mathbf{Q}$ and using Eqs. (8), (9), and (10) we get,

$$
\left[\begin{array}{ll}
\mathbf{M}_{B E} & \mathbf{M}_{B F} \\
\mathbf{M}_{F E} & \mathbf{M}_{F F}
\end{array}\right]\left\{\begin{array}{l}
\dot{\mathbf{D}}_{B} \\
\ddot{\mathbf{D}}_{F}
\end{array}\right\}+\left[\begin{array}{ll}
\mathbf{K}_{B E} & \mathbf{K}_{B F} \\
\mathbf{K}_{F E} & \mathbf{K}_{F F}
\end{array}\right]\left\{\begin{array}{l}
\mathbf{D}_{B} \\
\mathbf{D}_{F}
\end{array}\right\}=\left\{\begin{array}{l}
\mathbf{A}_{B}(t) \\
\mathbf{A}_{F}(t)
\end{array}\right\}
$$

where

$$
\begin{aligned}
& \mathbf{K}_{B E}=\mathbf{Q}_{B A} \mathbf{K}_{A A} \mathbf{Q}_{B A}^{\mathrm{T}} \\
& \mathbf{K}_{B F}=\mathbf{K}_{F B}^{\mathrm{T}}=\mathbf{Q}_{B A} \mathbf{K}_{A F}
\end{aligned}
$$

and

$$
\begin{gathered}
\mathbf{M}_{B B}=\mathbf{Q}_{B A} \mathbf{M}_{A A} \mathbf{Q}_{B A}^{\mathrm{T}} \\
\mathbf{M}_{B F}=\mathbf{M}_{F E}^{\mathrm{T}}=\mathbf{Q}_{E A} \mathbf{M}_{A F}
\end{gathered}
$$


The final mass matrix after adding the mass inertia of the rigid body will be as follows:

$$
\mathbf{M}_{E E}^{*}=\mathbf{M}_{E E}+\mathbf{M}_{\varepsilon}
$$

where, $\mathbf{M}_{C}$ is a $6 \times 6$ matrix with top left $3 \times 3$ sub-matrix as $m \mathbf{I}_{3}$ and right bottom corner $3 \times 3$ sub-matrix as the inertia matrix. The equation of motion for platform in the nodal form after the full assembly can be written as

$$
\begin{gathered}
M \ddot{\mathbf{x}}(t)+\mathbf{L} \dot{\mathbf{x}}(t)+\mathbf{K} \mathbf{x}(t)=B_{0} \mathbf{u} \\
\mathbf{y}=\mathbf{C}_{o q} \mathbf{x}+\mathbf{C}_{0 v} \dot{\mathbf{x}}
\end{gathered}
$$

where $\mathbf{M}, \mathbf{L}$ and $\mathbf{K}$ are the mass, damping and stiffness matrices and $\mathbf{x}, \dot{\mathbf{x}}$ and $\ddot{\mathbf{x}}$ are the nodal displacement, nodal velocity $\&$ nodal acceleration respectively. $\mathbf{B}_{0} \mathbf{u}$ is the external force vector, $\mathbf{y}$ is the output vector, $\mathbf{C}_{o q}$ is output displacement matrix and $\mathbf{C}_{o v}$ is output velocity matrix. In Eq. (15), the damping matrix is assumed to be a linear combination of stiffness and mass matrices as $\mathbf{L}=\alpha \mathbf{K}+\beta \mathbf{M}$ where $\alpha$ and $\beta$ are nonnegative scalars.

\subsection{Constitutive equations of the piezo actuators and sensors}

The linear piezoelectric coupling between the elastic field and the electric field can be expressed by the direct and the converse piezoelectric equations respectively [28]:

$(S)=\left[s^{\mathrm{E}}\right](\mathbf{T})+[\mathrm{d}][\mathrm{E}]$

$$
\{\mathbf{H}\}=[\mathbf{d}]\{\mathbf{T}\}+\left[\mathbf{\varepsilon}^{\mathbf{S}}\right]\{\mathbf{E}\}
$$

where, $\{\mathbf{s}\}$ is the strain vector, $\{\mathbf{T}\}$ the stress vector, $\{\mathbf{E}\}$ is the electric field, $\{\mathbf{H}\}$ is the electric displacement, $\left[\mathbf{s}^{\mathrm{E}}\right]$ is the compliance matrix when the electric field is constant, [d] is a matrix which relates electric displacement vector $\mathbf{H}$ to stress under a zero electric field matrix, $\left[\mathbf{\varepsilon}^{\mathbf{s}}\right]$ is the dielectric constant matrix under constant stress. For a piezoelectric strip with thickness $h_{p} \ll h_{b}$, where subscript $p$ stands for piezo and 
subscript $\mathrm{b}$ stands for beam, a voltage $\mathrm{V}$ applied to the electrodes will produce electric field $\mathrm{V} / \mathrm{h}_{\mathrm{p}}$. The constitutive equation in one dimensional can be written as

$$
\sigma_{11}=E_{p} \varepsilon_{11}-e_{31} \frac{v}{h_{p}},
$$

where $\sigma_{11}$ is the longitudinal stress, $\varepsilon_{11}$ is the longitudinal strain and $\mathbf{E}_{\mathrm{p}}$ denotes the Young's modulus of the piezo and $e_{31}=E_{p} d_{31}$ where $d_{31}$ is piezoelectric coupling coefficient.

\subsubsection{Modeling of smart single fold beam platform}

Active vibration control of the flexible platform has been studied using the finite element model based on the Euler-Bernoulli beam theory. Each of the four beams is discretized into 7 elements (Fig. 1). The vertical elements are thin elements in each folded beam and they are bonded with an actuator and sensor pair on either side of its surface and the horizontal elements are normal thick beam elements. Thus, in each of the folded beams, the vertical elements are smart beam elements and the horizontal elements are normal beam elements. 


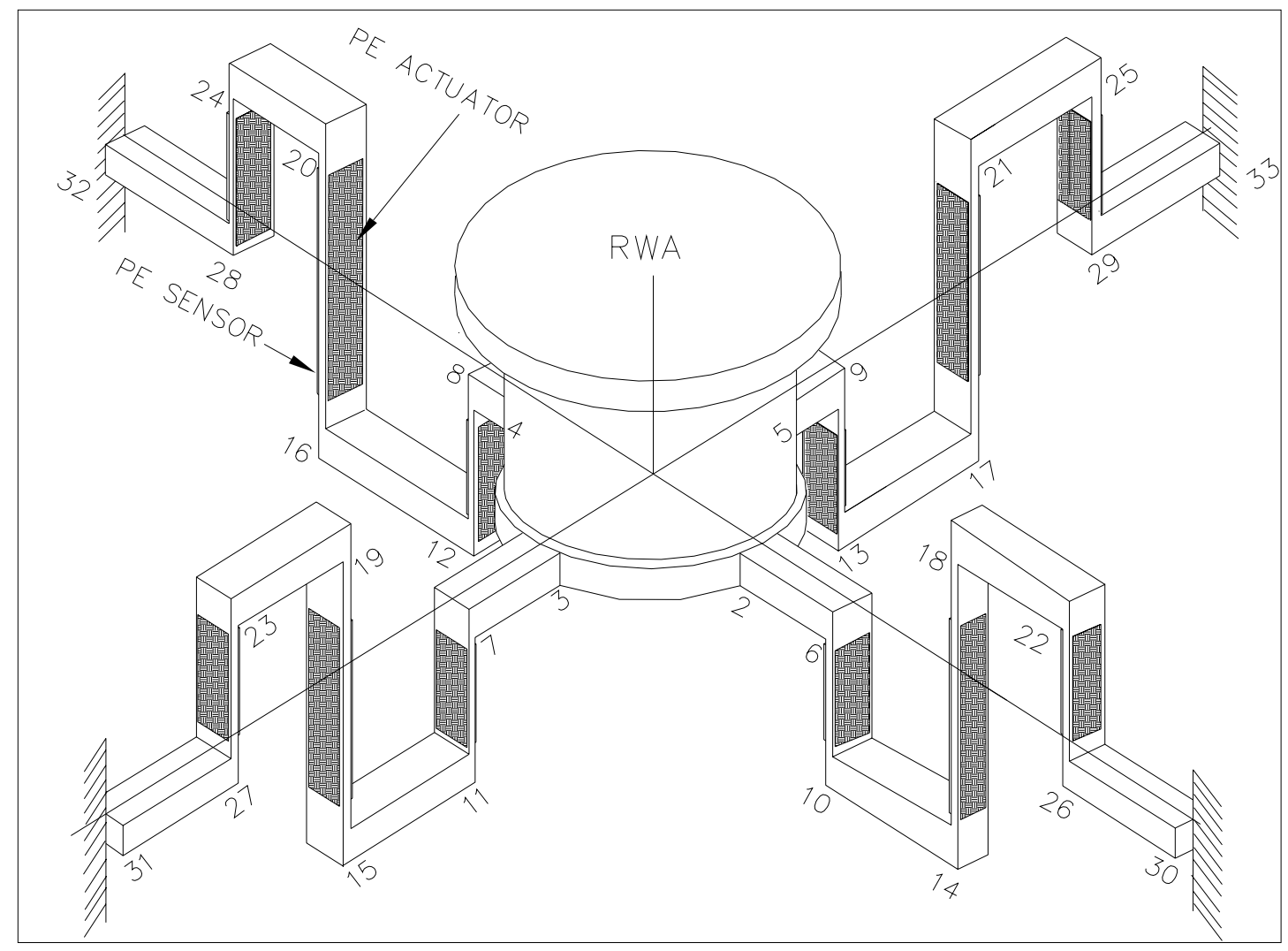

Figure 4 -- Smart folded beam platform.

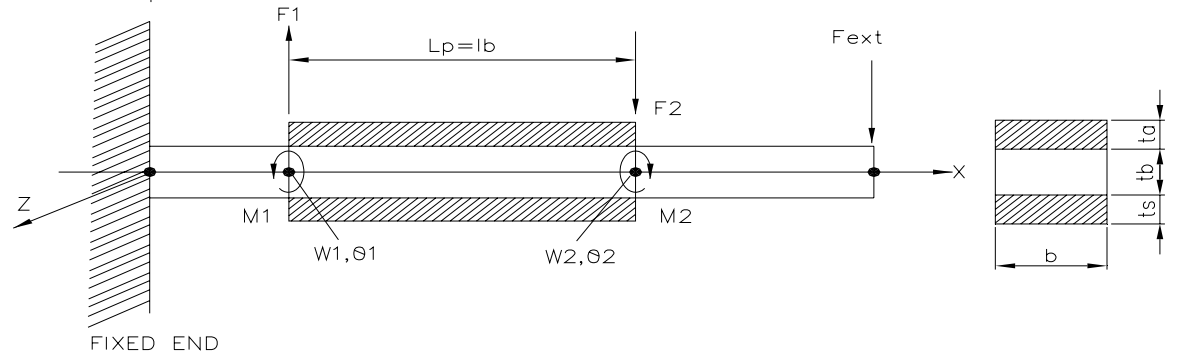

Figure 5 -- A typical smart element.

Table 2

Physical properties of smart beam element.

\begin{tabular}{ll}
\hline Width of element(Beam/PZT) & $0.025 \mathrm{~m}$ \\
Depth of piezo actuator/sensor & $0.00035 \mathrm{~m}$ \\
$E_{0}$, Modulus of elasticity of beam element & $21000 \mathrm{GPa}$ \\
$E_{\text {p }}$ Modulus of elasticity of piezo element & $13900 \mathrm{GPa}$
\end{tabular}




\begin{tabular}{ll}
\hline$G_{b}$, Modulus of rigidity of beam element & $7000 \mathrm{GPa}$ \\
Density of beam element $\left(\rho_{b}\right)$ & $7800 \mathrm{~kg} / \mathrm{m} 3$ \\
Density of PZT element $\left(\rho_{p}\right)$ & $7500 \mathrm{~kg} / \mathrm{m} 3$ \\
PZT Strain constant $\left(g_{31}\right)$ & $125 \times 10^{-12} \mathrm{~m} / \mathrm{V}$ \\
PZT Stress constant $\left(G_{31}\right)$ & $10.5 \times 10^{-3} \mathrm{~V} \mathrm{~m} / \mathrm{N}$ \\
\hline
\end{tabular}

\subsubsection{Smart element formulation}

The vertical element with piezoelectric patch as shown in Fig. 4 is assumed to have the axial, transverse and rotation degrees of freedom at each node. The electric degree of freedom is used as a sensor or actuator voltage. The kinematics of the model is derived based on Euler-Bernoulli beam theory [28, 29, 30]. Assuming the transverse shear strain in the base beam to be negligible, the longitudinal normal strain at a point in the base beam and in the piezoelectric layer is given as

$$
\begin{aligned}
& \left(\boldsymbol{\varepsilon}_{x x}\right)_{b}=\left(\boldsymbol{\varepsilon}_{x x}(x, z, t)\right)_{b}=\left[\left[\mathbf{N}_{u}^{\prime}\right]-z\left[\mathbf{N}_{w}^{\prime \prime}\right]\right]\left\{\begin{array}{l}
\overline{\mathbf{u}} \\
\overline{\mathbf{w}}
\end{array}\right\} \\
& \left(\boldsymbol{\varepsilon}_{x x}\right)_{p}=\left(\boldsymbol{\varepsilon}_{x x}\left(x_{r} z_{z} t\right)\right)_{p}=\left[\left[\mathbf{N}_{u}^{\prime}\right]-\left(\frac{k_{b}}{2}+z_{p}\right)\left[\mathbf{N}_{w}^{n}\right]\right]\{\overline{\overline{\mathbf{u}}}\}
\end{aligned}
$$

Here, $\mathbf{N}_{u}$ and $\mathbf{N}_{w}$ are the linear and cubic shape functions, $h_{b}$ and $z_{p}$ are thickness of beam and piezo strip and $\overline{\mathbf{u}}$ and $\overline{\mathbf{w}}$ are nodal degrees of freedom. The stiffness and mass matrices are developed using energy methods as described below.

\subsubsection{Strain energy and Stiffness matrix}

The strain energy stored in a deformed beam of length $L$, width $b$, thickness $h_{b}$ and $h_{p}$ is given by

$$
U=U(t)=U_{E b}+U_{E p}=\frac{1}{2} b \int_{0}^{L} \int_{-\frac{h_{b}}{2}}^{\frac{h_{b}}{2}}\left(E(x, z)\left(\varepsilon_{x x}(x, z, t)\right)^{2}\right) d z d x
$$


where, $U_{E b}$ and $U_{E q}$ are strain energies of beam and piezo strip elements and are given as

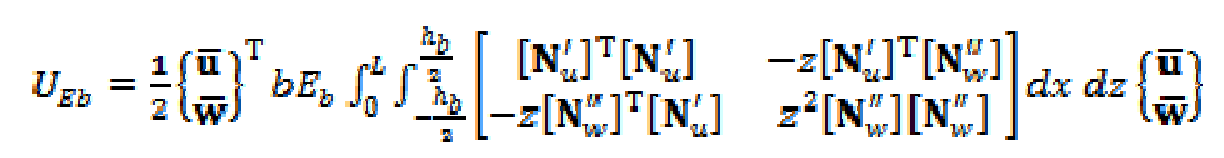

$U_{E p}=$

$$
\frac{1}{2}\{\overline{\overline{\mathbf{u}}}\}^{\mathrm{T}} b E_{p} \int_{0}^{L} \int_{0}^{h_{p}}\left[\begin{array}{cc}
\left.\left[\mathbf{N}_{u}^{\prime}\right]\right]^{\mathrm{T}}\left[\mathbf{N}_{u}^{\prime}\right] & -\left(\frac{h_{p}}{2}+z_{p}\right)\left[\mathbf{N}_{u}^{\prime}\right]^{\mathbf{T}}\left[\mathbf{N}_{w}^{v}\right] \\
-\left(\frac{h_{p}}{2}+z_{p}\right)\left[\mathbf{N}_{w}^{\prime \prime}\right]^{\mathrm{T}}\left[\mathbf{N}_{u}^{\prime}\right] & \left(\frac{k_{p}}{2}+z_{p}\right)^{2}\left[\mathbf{N}_{w}^{u t}\right]\left[\mathbf{N}_{w}^{u t}\right]
\end{array}\right] d z_{p} d x\{\overline{\overline{\mathbf{u}}}\}
$$

In the above equations, $E_{b}$ and $E_{p}$ are the modulus of elasticity of beam and piezo materials. These strain energy terms contribute to the stiffness matrix which is given as

$$
[\mathbf{K}]=\left[\mathbf{K}_{z b}\right]+\left[\mathbf{K}_{E p}\right]
$$

\subsubsection{Kinetic energy and Mass matrix}

The kinetic energy of beam of width $b$ and length $L$ is given by

$$
\begin{gathered}
T=T(t)=\frac{1}{2} b \int_{0}^{L} \int_{-\frac{z}{2}}^{\frac{z}{2}} p(x, z)\left((\dot{\mathbf{w}}(x, z, t))^{2}+(\dot{\mathbf{u}}(x, z, t))^{2}\right) d z d x \\
T=T_{w}+T_{u}=T_{w}+\left(T_{u b}+T_{u p}\right)
\end{gathered}
$$

For a beam with uniform density and thickness, the kinetic energy associated with the transverse motion $T_{w}$ and longitudinal motion $\left(T_{u b}, T_{u p}\right)$ of the beams are given by

$$
\begin{aligned}
& T_{w}=\frac{1}{2}\left\{\begin{array}{l}
\{\dot{\bar{n}}\} \\
\{\dot{\bar{w}}\}
\end{array}\right\}^{\mathrm{T}} b\left(\rho_{b} h_{b}+\rho_{p} h_{p}\right) \int_{0}^{L}\left[\begin{array}{cc}
{[0]} & {[0]} \\
{[0]} & {\left[\mathbf{N}_{w w}\right]^{\mathrm{T}}\left[\mathbf{N}_{w}\right]}
\end{array}\right] d x\left\{\begin{array}{l}
\{\dot{\bar{n}}\} \\
\{\dot{\mathbf{w}}\}
\end{array}\right\} \\
& T_{u b}=\frac{1}{2}\left\{\begin{array}{l}
\{\dot{\overline{\mathbf{u}}}\} \\
\{\dot{\overline{\mathbf{w}}}\}
\end{array}\right\} \quad b \rho_{b} \int_{0}^{L} \int_{-\frac{h_{b}}{z}}^{\frac{h_{b}}{z}}\left[\begin{array}{cc}
{\left[\mathbf{N}_{u}\right]^{\mathrm{T}}\left[\mathbf{N}_{u}\right]} & -z\left[\mathbf{N}_{w}^{t}\right]^{\mathrm{T}}\left[\mathbf{N}_{u}\right] \\
-z\left[\mathbf{N}_{w}^{t}\right]^{\mathrm{T}}\left[\mathbf{N}_{w s}\right] & z^{2}\left[\mathbf{N}_{w}^{t}\right]^{\mathrm{T}}\left[\mathbf{N}_{w}^{t}\right]
\end{array}\right] d z d x\left\{\begin{array}{l}
\{\dot{\overline{\mathbf{u}}}\} \\
\{\dot{\mathbf{w}}\}
\end{array}\right\}
\end{aligned}
$$




$$
\begin{aligned}
& T_{u p}= \\
& \frac{1}{2}\left\{\begin{array}{l}
\{\dot{\mathbf{u}}\} \\
\{\overline{\mathbf{w}}\}
\end{array}\right\}^{\mathrm{T}} b \rho_{p} \int_{0}^{L} \int_{0}^{h_{p}}\left[\begin{array}{cc}
{\left[\mathbf{N}_{u}\right]^{\mathrm{T}}\left[\mathbf{N}_{u}\right]} & -\left(\frac{h_{b}}{2}+z_{p}\right)\left[\mathbf{N}_{w}^{\prime}\right]^{\mathrm{T}}\left[\mathbf{N}_{u}\right] \\
-\left(\frac{h_{b}}{2}+z_{p}\right)\left[\mathbf{N}_{w}^{\prime}\right]^{\mathrm{T}}\left[\mathbf{N}_{u}\right] & z^{2}\left[\mathbf{N}_{w}^{\prime}\right]^{\mathrm{T}}\left[\mathbf{N}_{w}^{\prime}\right]
\end{array}\right] d z_{p} d x\left\{\begin{array}{l}
\{\overline{\mathbf{u}}\} \\
\{\overline{\mathbf{w}}]
\end{array}\right\}(
\end{aligned}
$$

The densities of beam and piezo materials are $\rho_{b}$ and $\rho_{p}$ respectively. These expressions lead to the following element mass matrix

$$
[\mathbf{M}]=\left[\mathbf{M}_{w}\right]+\left[\mathbf{M}_{u}\right]=\left[\mathbf{M}_{w}\right]+\left(\left[\mathbf{M}_{u b}\right]+\left[\mathbf{M}_{u p}\right]\right)
$$

\subsubsection{Sensor equation}

The sensor equation is derived from the direct piezoelectric equation as described in [30]. The electric displacement developed on the sensor surface is directly proportional to the stress acting on the sensor. If the polling is done along the thickness direction of the sensors with the electrodes on the upper and lower surfaces, then the electric displacement $\mathbf{H}_{z}$ is given as

$$
\mathbf{H}_{y}=d_{31} E_{p} \mathbf{\varepsilon}_{x}=e_{31} \mathbf{\varepsilon}_{x}
$$

where $d_{31}$ is the piezoelectric constant, $e_{31}$ is the piezoelectric stress / charge constant, $s_{x}$ is the strain produced and $E_{p}$ is the Young's modulus. The total charge $\mathbf{Q}(t)$ developed on the sensor surface (due to the strain) is the spatial summation of all the point charges developed on the sensor layer and is given by

$$
\mathbf{i}(t)=\frac{d 0(t)}{d t}=\frac{d}{d t} \int_{A} \mathbf{H}_{g} d A=\frac{d}{d t} \int_{A} e_{31} \mathbf{z}_{x} d A
$$

Since the strain $\varepsilon_{x}$ of the testing structure at a point can be expressed in terms of the second spatial derivative of the displacement function $\mathbf{w}^{\prime \prime}(x, t)$ as $\boldsymbol{\varepsilon}_{x}=z \frac{d^{2} \mathbf{w}}{d x^{2}}$, where $z$ is a coordinate of the point on the beam with respect to the axis of the beam, Eq. (30) can be written as

$$
\mathrm{i}(t)=\int_{A} e_{31} z \mathbf{N}_{w}^{\mathrm{I}} \frac{d}{d t}(\bar{w}) d A
$$


where $z=\left(\frac{t_{b}}{2}+t_{a}\right)$. The output current of the piezo sensor measures the moment rate of the flexible beam. This current is converted into the open circuit sensor voltage $\boldsymbol{V}^{s}(t)$ using a signal conditioning device with gain $G_{e}$ which is then applied to an actuator with a suitable controller gain. Thus, the sensor output voltage $\boldsymbol{V}^{\boldsymbol{s}}(\boldsymbol{t})$ is obtained as

$$
\mathbf{V}^{s}(t)=G_{c} e_{31} z b \int_{0}^{l_{p}} \mathbf{N}_{\mathrm{w}}^{\mathrm{T}} \frac{d}{d t}(\overline{\mathbf{w}}) d x
$$

which is the signal conditioning gain $G_{\theta}$ multiplied by the closed circuit current $t(t)$ generated by the piezoelectric lamina. The sensor output voltage can further be written for the beam elements as

$$
\mathbf{V}^{s}(t)=\left[\begin{array}{lllll}
0-G_{c} e_{51} z b & 0 & G_{c} e_{01} z b
\end{array}\right]\{\overline{\mathbf{w}}\}=G_{c} e_{51} z b\left[\begin{array}{lll}
0-1 & 0 & 1
\end{array}\right]\{\overline{\mathbf{w}}\}=\mathbf{P}^{\mathrm{T}}\{\dot{w}\}(33)
$$

\subsubsection{Actuator equation}

The actuator equation is derived from the converse piezoelectric equation as described in [30]. The strain $\boldsymbol{\varepsilon}_{a}$ developed by the electric field $\mathbf{E}_{f}$ on the actuator layer is given by

$$
\varepsilon_{a}=d_{31} \mathbf{E}_{f}
$$

where $d_{31}$ is the piezoelectric constant. When the input voltage $\mathbf{V}^{\Omega}(t)$ is applied to the piezoelectric actuator in the thickness direction $t_{a}$, the electric field $\mathbf{E}_{\boldsymbol{f}}$ and the stress $\boldsymbol{\sigma}_{a}$ developed by the actuator is given by

$$
\mathbf{E}_{f}=\frac{v^{a}(t)}{t_{a}} \text { and } \sigma_{a}=E_{p} d_{31} \frac{v^{a}(t)}{t_{a}}
$$

where, $E_{p}$ is the young's modulus of the piezoelectric layer. Because of this stress in the structure, bending moments act at nodes. In general, the expression for the bending moment in a small cross section of the piezoelectric element is given by

$$
d \mathbf{M}_{a}=E_{p} I_{p} \frac{d^{\mathrm{z}} \mathrm{w}}{d x^{2}}
$$


Since the strain $\mathbf{E}_{a}=z \frac{d^{2} \mathbf{w}}{d x^{2}}$ which is also equal to $\frac{\sigma_{a}}{E_{p}}$, the bending moment in the small cross section can be finally obtained as $d \mathbf{M}_{a}=\boldsymbol{\sigma}_{a} \mathbf{z}$. The resultant moment $\mathbf{M}_{a}$ acting on the beam element due to the applied voltage $V^{a}$ is determined by integrating the Eq. (36) throughout the structure thickness as

$$
\mathbf{M}_{a}=\int z \sigma_{a} d z
$$

which after simplifying becomes

$$
\mathbf{M}_{a}=E_{p} d_{31} \bar{z} \mathbf{V}^{a}(t)
$$

where $\bar{z}=\left(\frac{t_{a}+t_{b}}{2}\right)$ is the distance between neutral axis of the beam and the piezoelectric layer. The control force $\mathbf{F}_{\text {otrl }}$ produced by the actuator that is applied on the beam element is obtained using the Eq. (38) as

$$
\mathbf{F}_{\text {etrl }}=E_{p} d_{31} \bar{z} \int \mathbf{w}^{\prime}\left(x_{q} t\right) d x \mathbf{V}^{a}(t)
$$

which when expressed in terms of the control input to the actuator $\mathbf{v}^{a}(t)$ becomes

$$
\mathbf{F}_{\text {otrl }}=\mathbf{h} \mathbf{V}^{a}(t)=\mathbf{h u}(t)
$$

In the above equation, the constant vector $\mathbf{h}$ is obtained as

$$
\mathbf{h}^{\mathrm{T}}=\left[\begin{array}{llll}
-E_{p} d_{31} b z & 0 & E_{p} d_{31} b z & 0
\end{array}\right]
$$

In the presence of external forces the total force vector becomes

$$
\mathbf{F}^{\mathrm{T}}=\mathbf{F}_{e x t}+\mathbf{F}_{e t r l} \text {. }
$$

\subsubsection{Dynamic equation of the smart beam}

The flexible platform shown in Fig. 4 has been designed to act as a mount for devices like a reaction wheel, which would have a maximum speed of $3600 \mathrm{rpm}$. This suggests that we need to control only those modes for which the frequency is less than $60 \mathrm{~Hz}$. Therefore in the dynamic model only the first four modes are considered. The dynamics of the platform is represented by the following differential equation

$$
\mathbf{M} \ddot{\mathbf{q}}+\mathbf{K q}=\mathbf{B}_{f} \mathbf{u}_{f}+\mathbf{B}_{c} \mathbf{u}_{\sigma}=\mathbf{F}_{e x t}+\mathbf{F}_{\sigma t r l}
$$


where $\mathbf{K}$ and $\mathbf{M}$ are taken from Eqs. (23) and (28), respectively and for a system with $n_{d}$ degrees of freedom the size of the mass and stiffness matrices is $n_{d} \mathrm{x} n_{d}$. In Eq. (43), $\mathbf{q}$ is the $n_{d} \times \mathbf{1}$ nodal displacement vector, $\ddot{\mathbf{q}}$ is the $n_{d} \times \mathbf{1}$ nodal acceleration vector, $\mathbf{u}_{f}$ is the $s \times 1$ input force vector, $\mathbf{u}_{\varepsilon}$ is the $t \mathrm{x} 1$ control force vector. The input force matrix $\mathbf{B}_{f}$ is $n_{d} \mathbf{x} s_{s}$ and the control force matrix $\mathbf{B}_{e}$ is $n_{d} \mathbf{x} t$. The modal form of Eq. (43) is derived by using the transformation $\mathbf{q}=\mathbf{\Phi} \mathbf{z}$, where $\mathbf{z}$ and $\ddot{\mathbf{z}}$ represent the modal displacement and modal acceleration respectively. Therefore,

$$
\mathbf{M} \boldsymbol{\Phi} \ddot{z}+\mathbf{K} \Phi \mathbf{z}=\mathbf{F}_{z x t}+\mathbf{F}_{a t r l}=\mathbf{F}^{t}
$$

Here, $\boldsymbol{\Phi}$ is the modal matrix of size $\left(n_{d} \times 4\right)$ and consists of the eigenvectors corresponding to the first four modes.

Pre-multiplying Eq. (44) by $\boldsymbol{\Phi}^{\mathrm{T}}$, we get

$$
\boldsymbol{\Phi}^{\mathrm{T}} \mathbf{M} \boldsymbol{\Phi} \ddot{z}+\boldsymbol{\Phi}^{\mathrm{T}} \mathbf{K} \boldsymbol{\Phi} \mathbf{z}=\boldsymbol{\Phi}^{\mathrm{T}} \mathbf{F}_{z a x t}+\boldsymbol{\Phi}^{\mathrm{T}} \mathbf{F}_{c t r l}
$$

which can be written as

$$
\mathbf{M}_{m} \ddot{\mathbf{z}}+\mathbf{K}_{m} \mathbf{z}=\mathbf{F}_{\text {ext }}^{*}+\mathbf{F}_{c t r l s}^{*}
$$

where $\mathbf{M}_{m}=\boldsymbol{\Phi}^{\mathrm{T}} \mathbf{M} \boldsymbol{\Phi}$ and $\mathbf{K}_{m}=\boldsymbol{\Phi}^{\mathrm{T}} \mathbf{K} \boldsymbol{\Phi}$ are the diagonalized mass and stiffness matrices.

By introducing the modal damping matrix $\mathbf{L}_{m}=\boldsymbol{\Phi}^{\mathrm{T}} \mathbf{L} \boldsymbol{\Phi}$ in the above Eq. (46), where $\mathbf{L}=\propto \mathbf{K}+\beta \mathbf{M}$, with $\propto$ and $\beta$ as nonnegative scalars, we get the dynamic equation of smart flexible beam platform with four modes as

$$
\mathbf{M}_{m} \ddot{\mathbf{z}}+\mathbf{L}_{m} \dot{\mathbf{z}}+\mathbf{K}_{m} \mathbf{z}=\boldsymbol{\Phi}^{\mathrm{T}} \mathbf{F}_{e x t}+\boldsymbol{\Phi}^{\mathrm{T}} \mathbf{F}_{a t r l}
$$

The state space model of the flexible platform of four folded beams with twelve inputs and twelve outputs is given in state space form as

$$
\dot{\mathbf{x}}=\mathbf{A x}+\mathbf{B u}
$$

where, $A$ and $B$ are given by 


$$
\begin{aligned}
& \mathbf{A}=\left[\begin{array}{cc}
\mathbf{0} & \mathbf{I} \\
-\mathbf{M}_{r s}^{-1} \mathbf{K}_{m L} & -\mathbf{M}_{s s}^{-1} \mathbf{I}_{s s}
\end{array}\right]_{\mathrm{WS}} \\
& \mathbf{B}-\left[\begin{array}{cc}
\mathbf{0} & \mathbf{0} \\
\mathbf{M}_{m}^{-1} \boldsymbol{\Phi}^{\mathrm{T}} \mathbf{h}_{1} & \cdots \cdots \cdot \mathbf{M}_{m}^{-1} \boldsymbol{\Phi}^{\mathrm{T}} \mathbf{h}_{12}
\end{array}\right]_{\mathrm{aw12}}
\end{aligned}
$$

and $\mathbf{u}$ is an input matrix. In Eq. (50), $\mathbf{h}$ is a constant vector which depends on the type of the actuator, its location on the beam, its characteristic properties and is given by

$$
\mathbf{h}^{T}=\left[\begin{array}{c}
h_{1} \\
h_{2} \\
: \\
h_{12}
\end{array}\right]_{12 \times 150}^{T}
$$

The output equation is

$$
\{\mathbf{y}(t)\}=[\mathbf{c}]\{\mathbf{x}(t)\}
$$

where,

$$
\mathbf{C}=\left[\begin{array}{ll}
\mathbf{0} & \mathbf{P}^{\mathrm{T}} \boldsymbol{\Phi}
\end{array}\right]_{12 x \mathrm{8}},
$$

and, $\mathbf{P}$ is a constant vector which depends on sensor characteristics and its location/position on the beam and is given as

$$
\mathbf{P}^{\mathrm{T}}=\left[\begin{array}{c}
\mathbf{P}_{1} \\
\mathbf{P}_{2} \\
\vdots \\
\mathbf{P}_{12}
\end{array}\right]_{12 \times 150}^{\mathrm{T}}
$$

\section{Passive control simulation results}

The equations developed in section 3.1, namely Eq. (14) were simulated using Matlab. Results obtained are discussed next. 


\subsection{Eigenvalue analysis}

\subsubsection{Natural frequencies of four beam platform (Symmetrical)}

In this case the four horizontal planar beams, as shown in Fig. 1, were placed symmetrically with respect to the folds. The top and bottom folds were terminated at 24 $\mathrm{mm}$ from the horizontal beam. Eigenvalue analysis was carried out to study the variation in natural frequency by varying the thickness of vertical beam members. The results have been listed in Table 3. The frequencies have been listed upto $60 \mathrm{~Hz}$ as the platform is expected to take a mount that has a maximum speed of $3600 \mathrm{rpm}$. It is observed that a decrease in thickness of vertical beam member lowers the frequency of the platform. The first eigenvalue is obtained as $-28.86 \mp j 103.49$ which has a negative real part. Although not presented here, all eigenvalues have been found to be negative, thereby implying that the system is well damped and stable.

\subsubsection{Natural frequencies of four beam platform (Un-Symmetrical)}

In this case the four horizontal planar beams were placed un-symmetrically with respect to top and bottom folds. Two types of unsymmetrical beams are considered. In the first type the horizontal beam is at a distance of $24 \mathrm{~mm}$ from the top fold and $36 \mathrm{~mm}$ from the bottom fold. In the second type the horizontal beam is placed from the top and bottom folds at a distance of $24 \mathrm{~mm}$ and $48 \mathrm{~mm}$ respectively. In either case frequencies were obtained for varying thickness of vertical beam members. Comparing the results in Table 3 , it is inferred that an increase in length of the vertical members, leads to reduction in frequency.

Table 3

Natural frequency $(\mathrm{Hz})$ of four beam platform.

\begin{tabular}{cccc}
\hline $\begin{array}{c}\text { Vertical beam } \\
\text { thickness }(\mathrm{m})\end{array}$ & $\begin{array}{c}\text { Symmetrical } \\
(0.024-0.024) \mathrm{m}\end{array}$ & $\begin{array}{c}\text { Symmetrical } \\
(0.024-0.036) \mathrm{m}\end{array}$ & $\begin{array}{c}\text { Un-symmetrical } \\
(0.024-0.048) \mathrm{m}\end{array}$ \\
\hline 0.001 & 17.100 & 13.320 & 10.555 \\
& 24.816 & 21.021 & 18.440 \\
& 37.833 & 32.552 & 28.709 \\
& 44.756 & 42.761 & 40.659 \\
& 74.134 & 67.172 & 60.723 \\
\hline 0.0008 & 13.275 & 10.134 & 7.908 \\
\hline
\end{tabular}




\begin{tabular}{cccc}
\hline 19.347 & 16.649 & 14.877 \\
31.358 & 26.864 & 23.562 \\
42.390 & 40.284 & 38.078 \\
70.239 & 62.926 & 56.252 \\
& & & 93.990 \\
\hline 0.0006 & 9.304 & 6.942 & 5.333 \\
& 13.566 & 11.820 & 10.713 \\
& 23.298 & 19.742 & 17.143 \\
& 39.864 & 37.701 & 38.402 \\
& 66.239 & 58.890 & 52.083 \\
& & 102.617 & 90.940 \\
\hline
\end{tabular}

\subsubsection{Natural frequencies for different number of folds}

The platform shown in Fig. 1 has only one fold. In order to investigate the design for more flexibility, numerical simulations were carried out by increasing the number of folds to two, three and four. It is seen that as the numbers of folds are increased, there is drop in the frequency. Similarly when the thickness of vertical members is reduced from $0.001 \mathrm{~m}$ to $0.0006 \mathrm{~m}$, there is further reduction in frequency. The results are tabulated in Table 4.

Table 4

Natural frequencies $(\mathrm{Hz})$ of a four beam platform for varying number of folds.

\begin{tabular}{ccccc}
\hline $\begin{array}{c}\text { Vertical beam } \\
\text { thickness }(\mathrm{m})\end{array}$ & One fold & Two folds & Three folds & Four folds \\
\hline 0.001 & 17.100 & 11.128 & 7.637 & 5.771 \\
& 24.816 & 15.010 & 10.729 & 8.595 \\
& 37.838 & 22.195 & 14.960 & 10.896 \\
& 44.756 & 33.173 & 27.913 & 24.429 \\
& 74.134 & 57.356 & 38.911 & 33.820 \\
0.0008 & 13.275 & 8.317 & 72.051 & 63.479 \\
& 19.347 & 11.144 & 5.557 & 4.167 \\
& 31.358 & 16.629 & 7.820 & 6.237 \\
& 42.390 & 35.551 & 27.147 & 7.920 \\
& 70.109 & 55.578 & 38.109 & 23.987 \\
0.0006 & & 92.938 & 71.288 & 60.272 \\
& 9.304 & 5.578 & 3.649 & 2.723 \\
& 13.566 & 7.443 & 5.142 & 4.092 \\
& 23.298 & 11.166 & 7.249 & 5.204 \\
& 39.864 & 34.092 & 26.493 & 23.543 \\
& 66.239 & 53.780 & 37.238 & 32.738 \\
& & 82.896 & 56.888 & 41.519 \\
& & & 56.897 & 41.601 \\
\hline
\end{tabular}




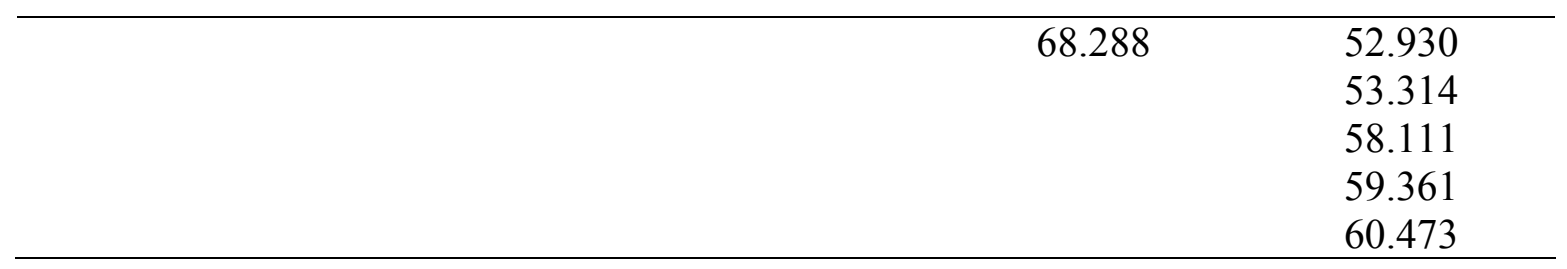

Thus, low frequencies for the platform can be achieved by:

(i) Increasing the number of folds,

(ii) Decreasing the thickness of vertical members,

(iii) Placing the horizontal beams un-symmetrically with respect to the top and bottom folds.

The flexible platform can therefore be used as a mounting device with an optimal set of design parameters to meet the frequency specification in any given application.

\subsection{Response Analysis}

\subsubsection{Free un-damped response analysis}

Time responses were computed from Eq. (14) by assuming the initial condition vector as $\mathbf{x}(\mathbf{0})=\{0.002,0.005,0.002,0, \ldots\}^{\mathrm{T}}$. Results corresponding to $2^{\text {nd }}$ and $4^{\text {th }}$ degree of freedom for the platform are shown in Fig. 6(a) and Fig. 6(b). It can be seen that the largest amplitude response in either case is as high as $\sim 4 \times 10^{-3} \mathrm{~m}$ and $\sim 4 \times 10^{-2} \mathrm{rad}$. All other degrees of freedom have lower response.

\subsubsection{Impulse response analysis}

For an external impulse of $1 \mathrm{~N}$ at $2^{\text {nd }}$ degree of freedom, the responses were calculated at all nodes. It is observed that for all degrees of freedom of the platform the peak responses are small and they damp out in a very short time. This behavior for the first two degrees of freedom has been depicted in Fig. 7(a) and Fig. 7(b). Since the damping ratio $(\zeta)$ for a metal structure generally lies between 0.01 and 0.05 , in this simulation, we consider $\varsigma_{1}=$ 0.025 for the first mode. For the other modes damping ratio [26] is calculated using the relation $\varsigma_{i} \approx \varsigma_{1}\left(\frac{\omega_{i}}{\omega_{1}}\right)^{e_{1}}, \quad\left(0.5 \leq e_{1} \leq 0.7\right)$. 


\subsubsection{Forced response analysis}

The response of the symmetrical flexible platform at the first two degrees of freedom subjected to a harmonic load of $5 \sin (24.816 t) \mathrm{N}$ at the first node is depicted in Fig. 8(a) and Fig. 8(b). It is observed that the amplitude of the response is of the order $10^{-5}$. Similar behavior has been observed at all other degrees of freedom too.

\subsubsection{Frequency response analysis}

For the one folded beam platform, the forced response analysis was carried out by varying the forcing frequency from $0-65 \mathrm{~Hz}$. The transfer receptances $\alpha_{12}$ and $\alpha_{32}$ are plotted in Fig. 9(a) and Fig. 9(b) respectively. The peaks are seen at the natural frequencies of the system. The damped and un-damped responses clearly demonstrate that platform system is quite stable.

\subsubsection{Modal responses}

Response of the first two modes plotted in Fig. 10(a) and Fig. 10(b) indicate that each response is a sinusoid of frequency equal to the natural frequency and of exponentially decaying amplitude proportional to modal damping $\varsigma_{i}$. Note that the higher frequency responses decay faster. 
(a)

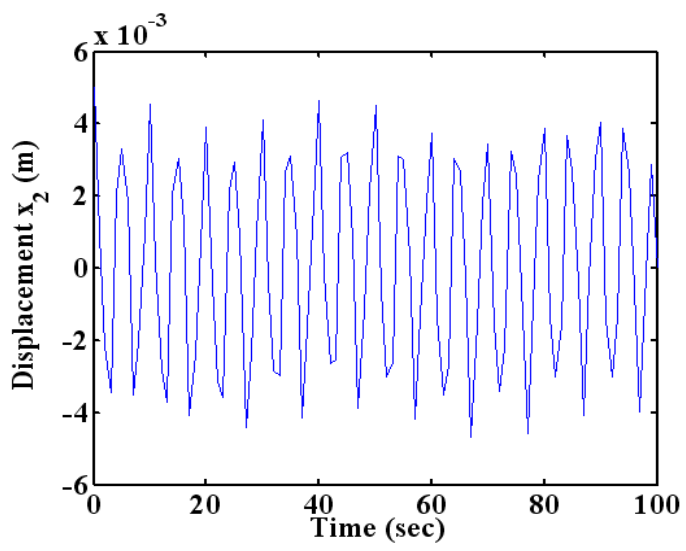

(b)

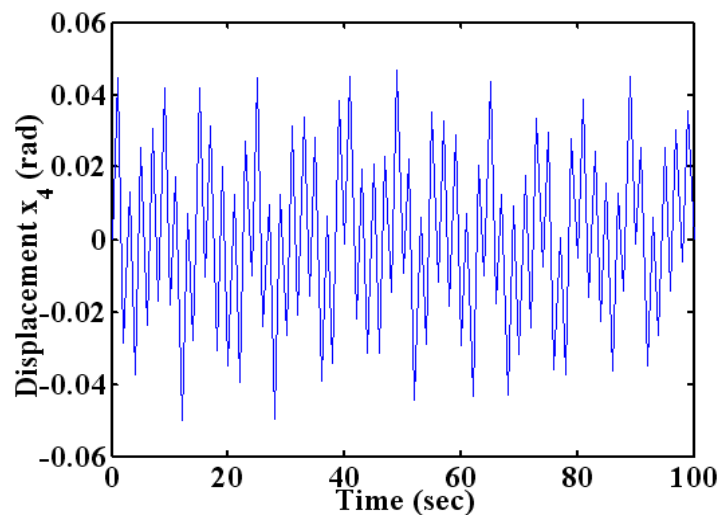

Figure 6 -- Time response of the platform (a) Response of $2^{\text {nd }}$ dof and (b) Response of $4^{\text {th }}$ dof.

(a)

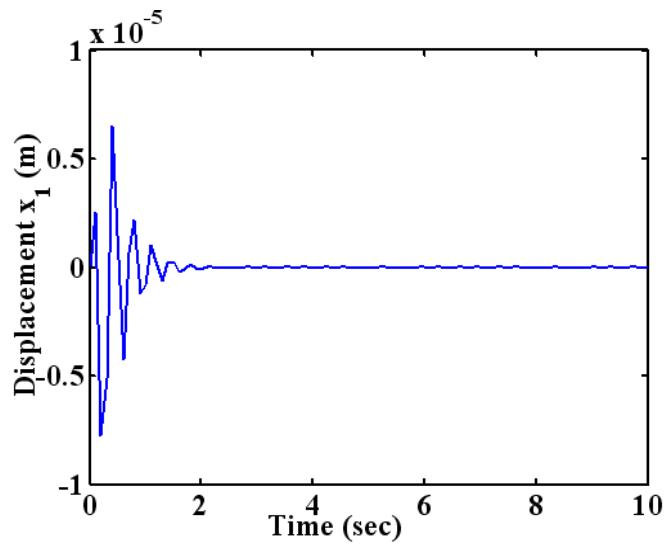

(b)

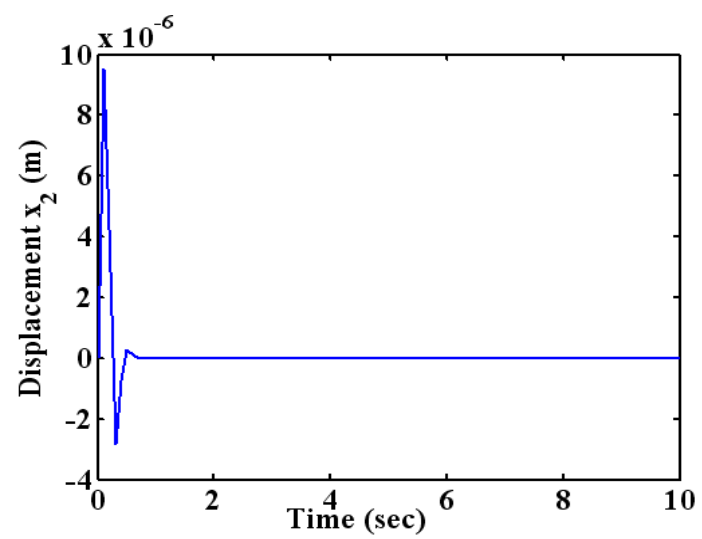

Figure 7 -- For an impulse of $1 \mathrm{~N}$ at $2^{\text {nd }}$ dof. (a) Response at $1^{\text {st }}$ dof and (b) Response at $2^{\text {nd }}$ dof. 
(a)

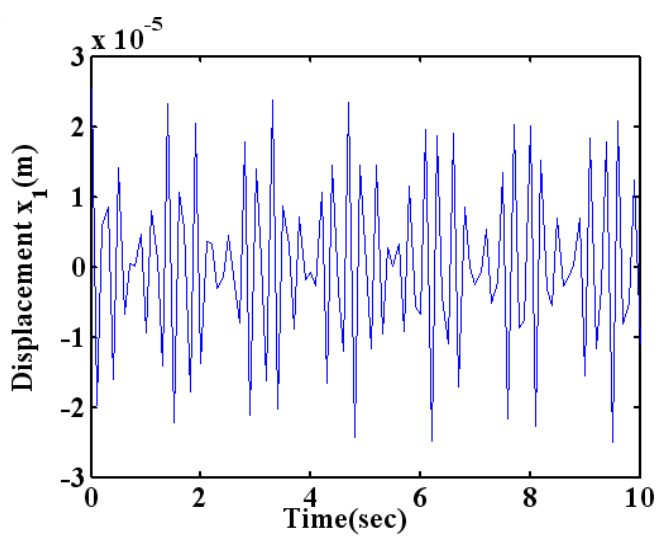

(b)

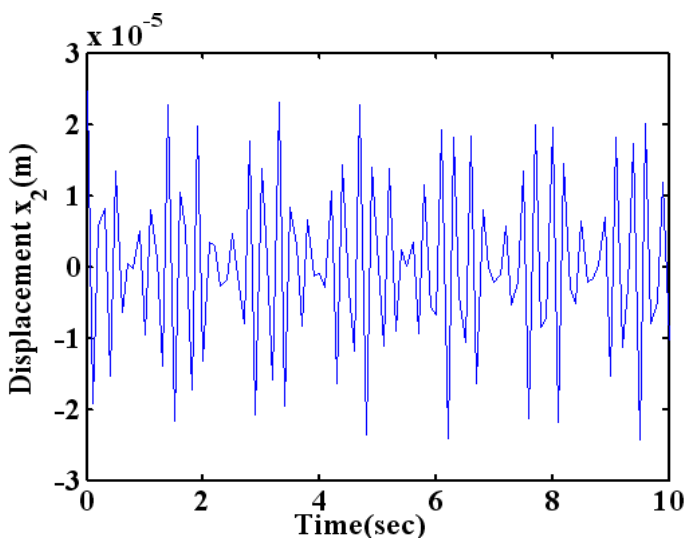

Figure 8 -- For a sinusoidal input (a) Response at $1^{\text {st }}$ DOF and (b) Response at $2^{\text {nd }}$ DOF.
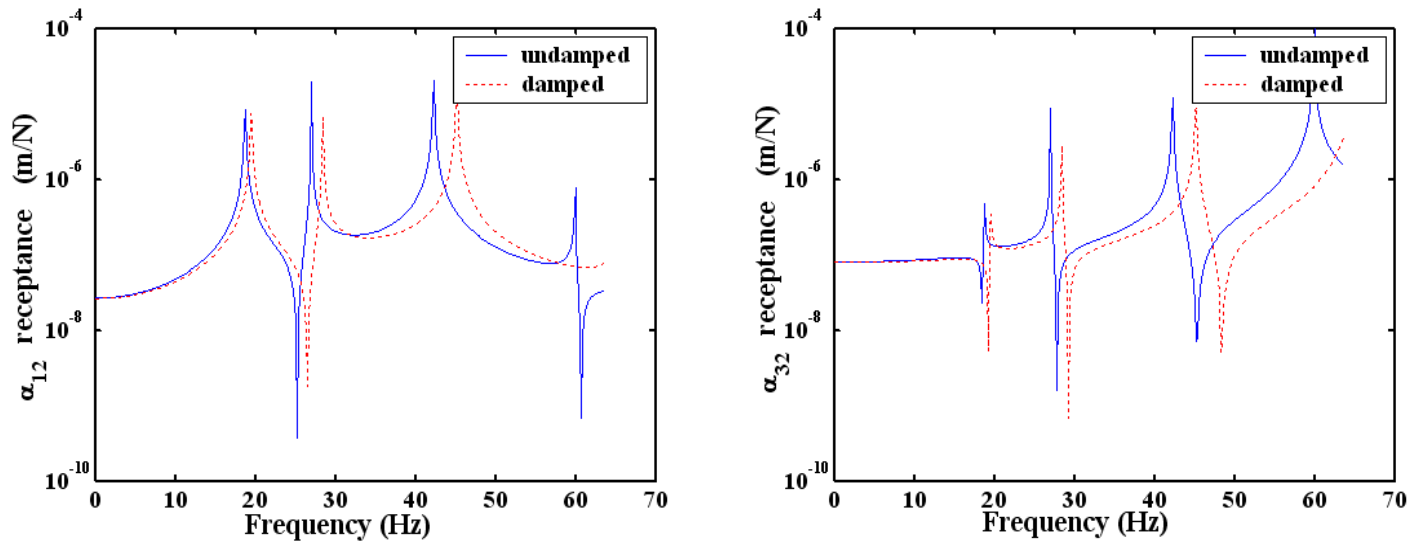

Figure 9 -- Damped and Un-damped forced frequency response plots.
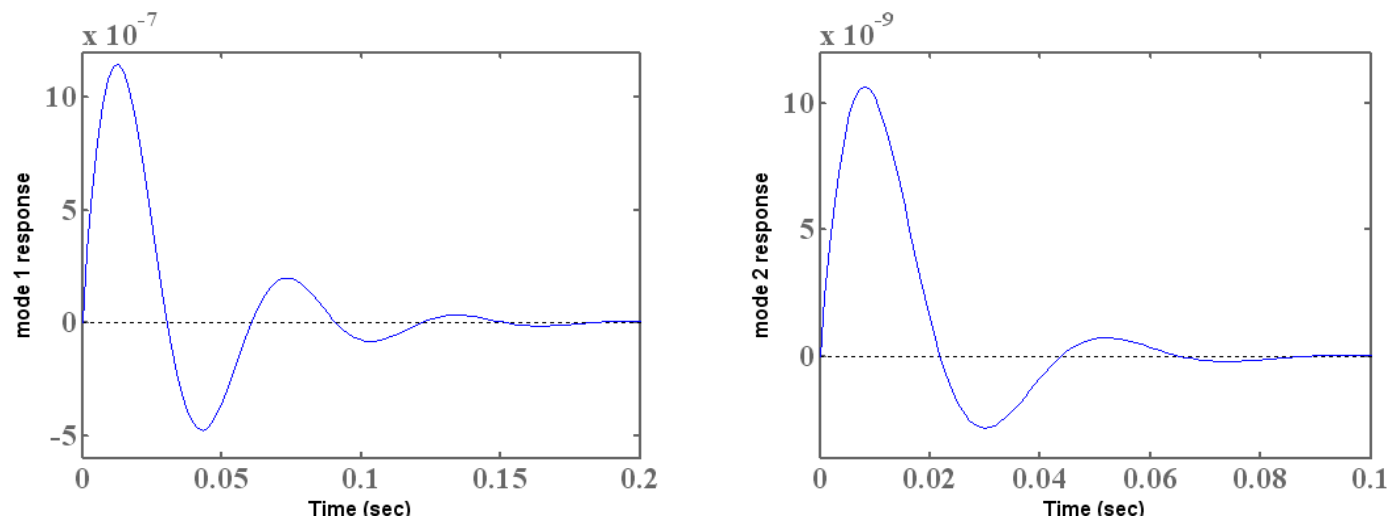

Figure 10 -- Modal response of first two modes. 


\subsection{Effectiveness of the Platform Isolator}

Platform isolation has been estimated for a typical symmetric flexible platform comprising of three folded beams. For vertical beams with thickness equal to $0.8 \mathrm{~mm}$ and a forcing frequency of $60 \mathrm{~Hz}$, it is found that the ratio of forcing frequency to the first natural frequency is 10.797 which amounts to an isolation of $99.0905 \%$.

\section{Active control simulation results}

Active vibration control of the flexible platform was studied using piezo-laminated beam elements. Two PZT layers were bonded on either side of the vertical beams to act as a sensor and actuator pair. Finite element formulation was done with the following assumptions:

(i) Sensor-actuator patches are placed on either side of the most flexible part of the four beams.

(ii) PZT sensor actuator patches are made of lead zirconate titanate material of $35 \mu \mathrm{m}$ thickness.

(iii) Length of both the piezoelectric sensor and actuator patch is equal to the length of one finite element.

(iv) Structural damping is proportional and is taken to be $\mathbf{L}_{m}=\alpha \mathbf{K}_{m}+\beta \mathbf{M}_{m}$; where $\alpha=0.0005, \beta=0.0002$. These values are deliberately assumed to be very low in order to study the effectiveness of active control on response.

Optimal control has been applied using the Linear Quadratic Regulator [23, 24]. The optimal control problem consists of solving for the feedback gain matrix, $\mathbf{G}$, such that the performance matrix $\boldsymbol{l}$ is minimal. The cost function to be minimized is given by

$$
J=\frac{1}{2} \int_{0}^{\infty}\left(\{\boldsymbol{x}\}^{T}[\mathbf{Q}(t)]\{\mathbf{x}\}+\{\mathbf{u}\}^{T}[\mathbf{R}(t)]\{\mathbf{u}\}\right) d t
$$


where $[\mathbf{Q}(t)]$ and $[\mathbf{R}(t)]$ are semi-positive definite and positive definite weighting matrices on the outputs and control inputs respectively. Assuming full state feedback, the control law is given by

$$
\{\mathbf{u}\}=-[\mathbf{G}]\{\mathbf{x}\}
$$

The above state feedback is applied to reduced order model considering only the first four modes of interest which correspond to disturbances of frequency less than $60 \mathrm{~Hz}$. Response of the system to various types of loading conditions is studied using Eq. (53) and is described below.

\subsection{Response to harmonic loading}

The dynamic response of the platform has been studied for sinusoidal load of $0.5 * \sin$ $\left(w_{i} * t\right) \mathrm{N}$ where, the forcing frequencies $\omega_{i}(i=1$ to 4$)$ are the first four natural frequencies. The vibration amplitudes are controlled using the LQR optimal control with weighing matrices (i) $\mathbf{Q}=10^{12} * \mathbf{I}_{\mathrm{g}}, \mathbf{R}=0.5 * \mathbf{I}_{12}$ and (ii) $\mathrm{Q}=10^{11} * \mathrm{I}_{\mathrm{g}}$, $\mathbf{R}=0.5 * \mathbf{I}_{12}$. The amplitudes of the modal response of first four modes are listed in

Table 5. The uncontrolled and controlled responses are compared in Figs. $11 \& 12$. The control brings about a significant reduction in amplitude for all four modes as indicated by the dark line. It is also seen that no resonance occurs for all four modes. Considering a single beam from Fig. 1, the actuator voltages developed in each vertical strip of the beam were recorded. Fig. 13 represents these voltages for the first mode which are observed to be within the PZT threshold. The voltage required for the longer vertical beam is more due to higher bending strain. The eigenvalues for the closed loop system listed in Table 6, show that there is a significant shift in the real part when the $Q=10^{12} * I_{8} \& \mathbf{R}=0.5 * I_{12}$. 
Table 5

Responses to harmonic loading.

\begin{tabular}{|c|c|c|c|c|}
\hline \multirow{2}{*}{$\begin{array}{l}\text { Exciting frequency } \\
\qquad(\mathrm{Hz})\end{array}$} & \multicolumn{2}{|c|}{ Amplitude of modal response (m) } & \multirow[t]{2}{*}{$\mathbf{Q}$} & \multirow[t]{2}{*}{$\mathbf{R}$} \\
\hline & Without control & With control & & \\
\hline 17.100 & $1.25 \times 10^{-5}$ & $0.15 \times 10^{-5}$ & $10^{12}$ & 0.5 \\
\hline 24.816 & $0.75 \times 10^{-5}$ & $0.2 \times 10^{-5}$ & $10^{12}$ & 0.5 \\
\hline 37.838 & $2.0 \times 10^{-5}$ & $0.25 \times 10^{-5}$ & $10^{12}$ & 0.5 \\
\hline 44.756 & $1.9 \times 10^{-5}$ & $0.25 \times 10^{-5}$ & $10^{12}$ & 0.5 \\
\hline
\end{tabular}

Table 6

Eigenvalues of closed loop when external force of $0.5 \leqslant \sin \left(\omega_{n}\right)_{i}=t \mathrm{~N}$ at $2^{\text {nd }}$ dof

Eigenvalues of open and closed loop

\begin{tabular}{cccccc}
\hline \multicolumn{2}{c}{ Without PZT control } & \multicolumn{3}{c}{ With PZT control actuators and sensors } \\
\hline Eigenvalues & Nat. & $\mathbf{Q}$ & $\mathbf{R}$ & Eigenvalues & Actuator \\
& Freq. (Hz) & & & & Voltage (V) \\
\hline$-1.6865 \pm 129.848 \mathrm{i}$ & 20.677 & $\mathbf{1 0 ^ { 1 2 }}$ & 0.5 & $-8.2685 \pm 129.624474 \mathrm{i}$ & Typical \\
$-3.1883 \pm 178.522 \mathrm{i}$ & 28.4316 & & & $-12.1349 \pm 178.104864 \mathrm{i}$ & voltages \\
$-7.5222 \pm 274.159 \mathrm{i}$ & 43.6723 & & & $-10.3124 \pm 274.376612 \mathrm{i}$ & $50,150,5$ \\
$-8.8554 \pm 297.445 \mathrm{i}$ & 47.3848 & & & $-15.5558 \pm 296.826947 \mathrm{i}$ & \\
\hline$-1.6865 \pm 129.848 \mathrm{i}$ & 20.677 & $\mathbf{1 0}$ & 0.5 & $-3.0817 \pm 129.8228 \mathrm{i}$ & Typical \\
$-3.1883 \pm 178.522 \mathrm{i}$ & 28.4316 & & & $-4.9099 \pm 178.48335 \mathrm{i}$ & voltages \\
& & & & $-7.8932 \pm 274.15381 \mathrm{i}$ & $8,25,0.5$ \\
$-7.5222 \pm 274.159 \mathrm{i}$ & 43.6723 & & & $-9.76861 \pm 297.4123 \mathrm{i}$ & \\
$-8.8554 \pm 297.445 \mathrm{i}$ & 47.3848 & & & & \\
\hline
\end{tabular}



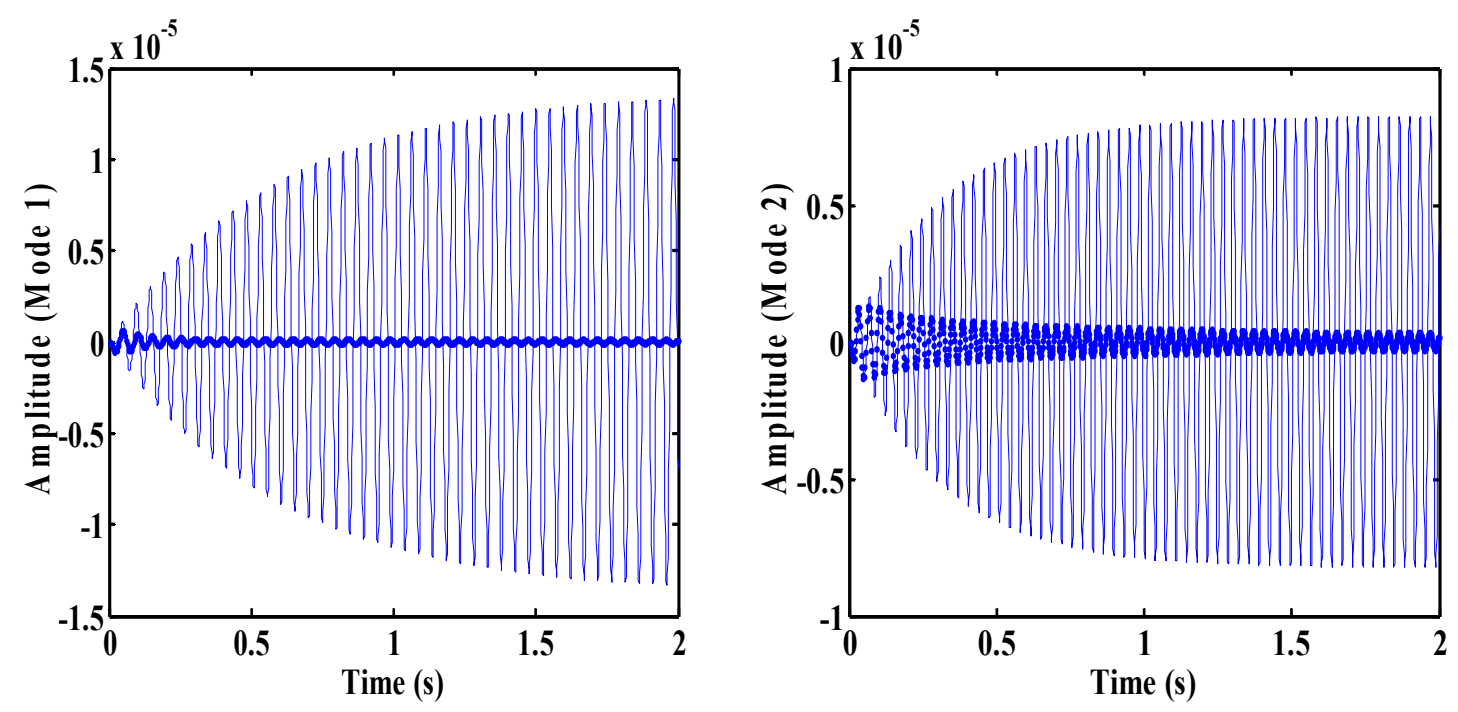

Figure 11 -- Modal response- $1^{\text {st }}$ and $2^{\text {nd }}$ mode.

_ uncontrolled response, _ controlled response.
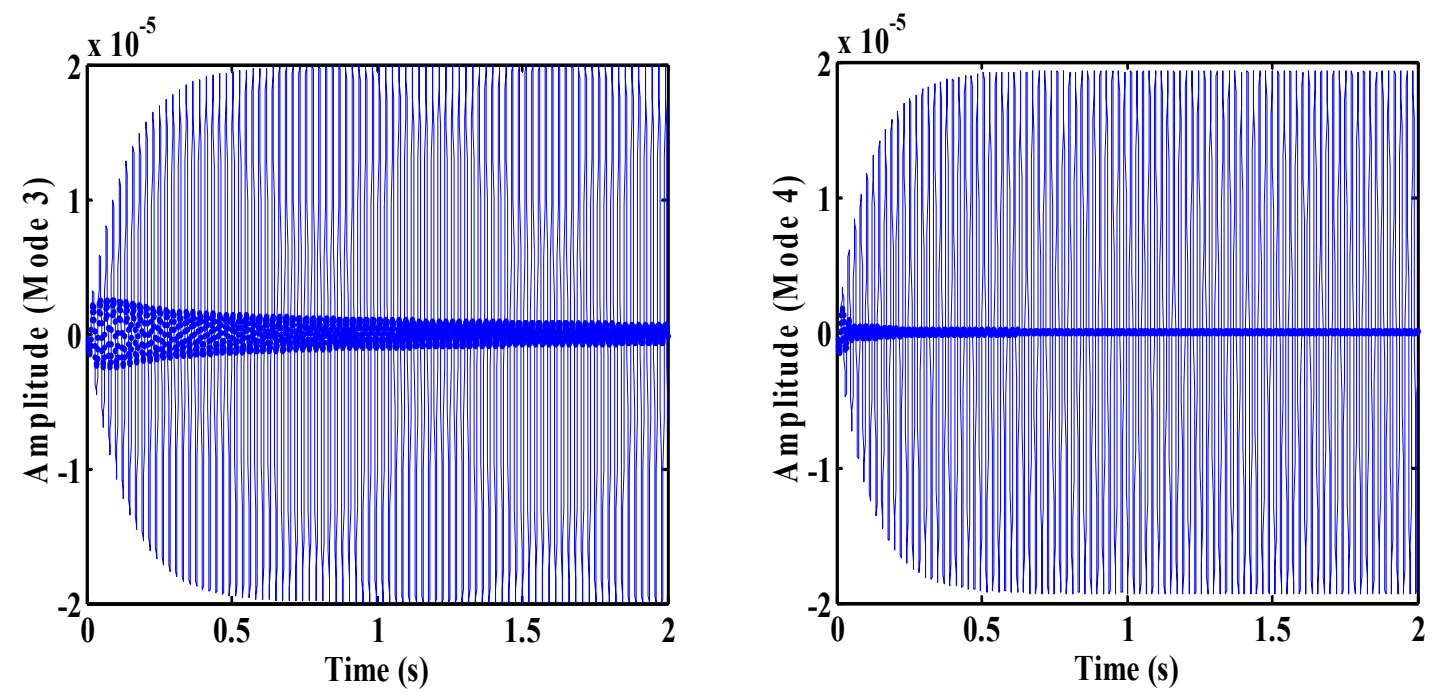

Figure 12 -- Modal response- $3^{\text {rd }}$ and $4^{\text {th }}$ mode. _ uncontrolled response, _ controlled response. 

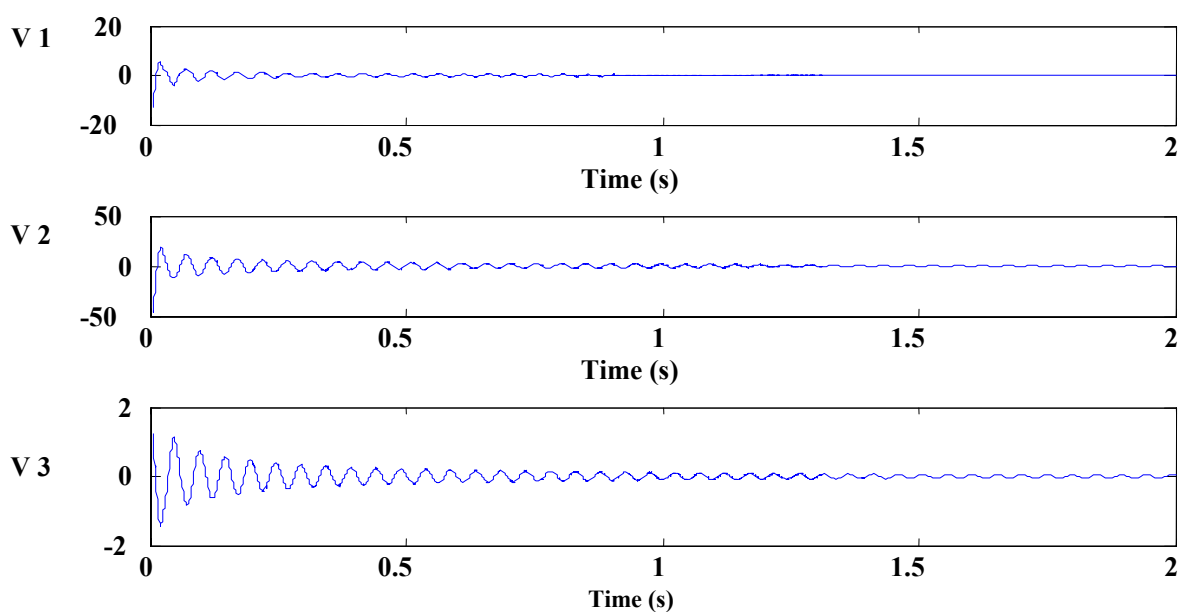

Figure 13 -- Actuator voltages for a single beam. $v_{1}$ and $v_{3}$ are the voltages in the smaller vertical strips and $v_{2}$ is the voltage in the longer vertical strip (Fig. 1).

\subsection{Response to initial condition}

The system is subjected to an initial displacement of $0.005 \mathrm{~m}$ at the second degree of freedom. The modal responses of first four modes are given in Table 7. It is seen that the dynamic response is more influenced by the third mode. The weighing matrices $\mathbf{Q}=10^{9} * \mathbf{I}_{8}$ and $\mathbf{R}=0.8 * \mathbf{I}_{12}$ have been chosen for control and the settling time is seen to be less than $0.5 \mathrm{~s}$ as shown in Fig. 14. The control voltages for the actuators plotted in Fig. 15 once again reflect that higher bending strain results in higher control voltage. The eigenvalues are given in Table $8 \& 9$ for controlled and un-controlled system. Although there is a small shift in the real part but the control is found to be significant with the chosen weighing matrices.

Table 7

Responses to initial condition.

\begin{tabular}{cccc}
\hline $\begin{array}{c}\text { Initial displacement at } \\
2^{\text {nd }} \text { dof }\end{array}$ & $\begin{array}{c}\text { Amplitude (m) of the first four } \\
\text { modes }\end{array}$ & $\mathbf{Q}$ & $\mathbf{R}$ \\
\hline $0.005 \mathrm{~m}$ & $\mathbf{1 . 0 \times 1 0 ^ { - 4 }}$ & $10^{9}$ & 0.8 \\
& $1.75 \times 10^{-4}$ & $10^{9}$ & 0.8 \\
\hline
\end{tabular}




\begin{tabular}{ccc}
\hline $2.0 \times 10^{-3}$ & $10^{9}$ & 0.8 \\
$1.50 \times 10^{-3}$ & $10^{9}$ & 0.8 \\
\hline
\end{tabular}

Table 8

For $\mathbf{Q}=10^{9} * \mathbf{I}_{8}$ and $\mathbf{R}=0.8 \leqslant \mathbf{I}_{12}$.

Eigen Values of Open and Closed loop

\begin{tabular}{cccccc}
\hline \multicolumn{2}{c}{ Without PZT control } & \multicolumn{5}{c}{ With PZT Control (Actuators and Sensors) } \\
\hline Eigen values & Nat.Freq. (Hz) & $\mathbf{Q}$ & $\mathbf{R}$ & Eigen values & Actuator Voltage \\
\hline$-1.6865 \pm 129.848 \mathrm{i}$ & 20.677 & $\mathbf{1 0 ^ { 9 }}$ & 0.8 & $-1.69889+129.8479 \mathrm{i}$ & Typical \\
$-3.1883 \pm 178.522 \mathrm{i}$ & 28.4316 & & & $-3.20197+178.522 \mathrm{i}$ & voltages \\
$-7.5222 \pm 274.159$ & 43.6723 & & & $-7.52468+274.1597 \mathrm{i}$ & $100,250,5$ \\
$-8.8554 \pm 297.445$ & 47.3848 & & & $-8.86153+297.4456 \mathrm{i}$ & \\
\hline
\end{tabular}

Table 9

For $\quad \mathbf{Q}=10^{10} * \mathbf{I}_{3}$ and $\mathbf{R}=0.8 * \mathbf{I}_{12}$,

Eigenvalues of Open and Closed loop

\begin{tabular}{cccccc}
\hline \multicolumn{2}{c}{ Without PZT control } & \multicolumn{5}{c}{ With PZT Control (Actuators and Sensors) } \\
\hline Eigenvalues & Natural & $\mathbf{Q}$ & $\mathbf{R}$ & Eigenvalues & Actuator Voltage \\
& Freq. (Hz) & & & & \\
\hline$-1.6865 \pm 129.848 \mathrm{i}$ & 20.677 & $\mathbf{1 0}^{\mathbf{1 0}}$ & 1.0 & $-1.782644+129.8468 \mathrm{i}$ & Typical voltages \\
$-3.1883 \pm 178.522 \mathrm{i}$ & 28.4316 & & & $-3.296029+1785208 \mathrm{i}$ & $75,250,15$ \\
$-7.5222 \pm 274.159 \mathrm{i}$ & 43.6723 & & & $-7.5415871+274.159 \mathrm{i}$ & \\
$-8.8554 \pm 297.445 \mathrm{i}$ & 47.3848 & & & $-8.90370+2.9744440 \mathrm{i}$ & \\
\hline
\end{tabular}



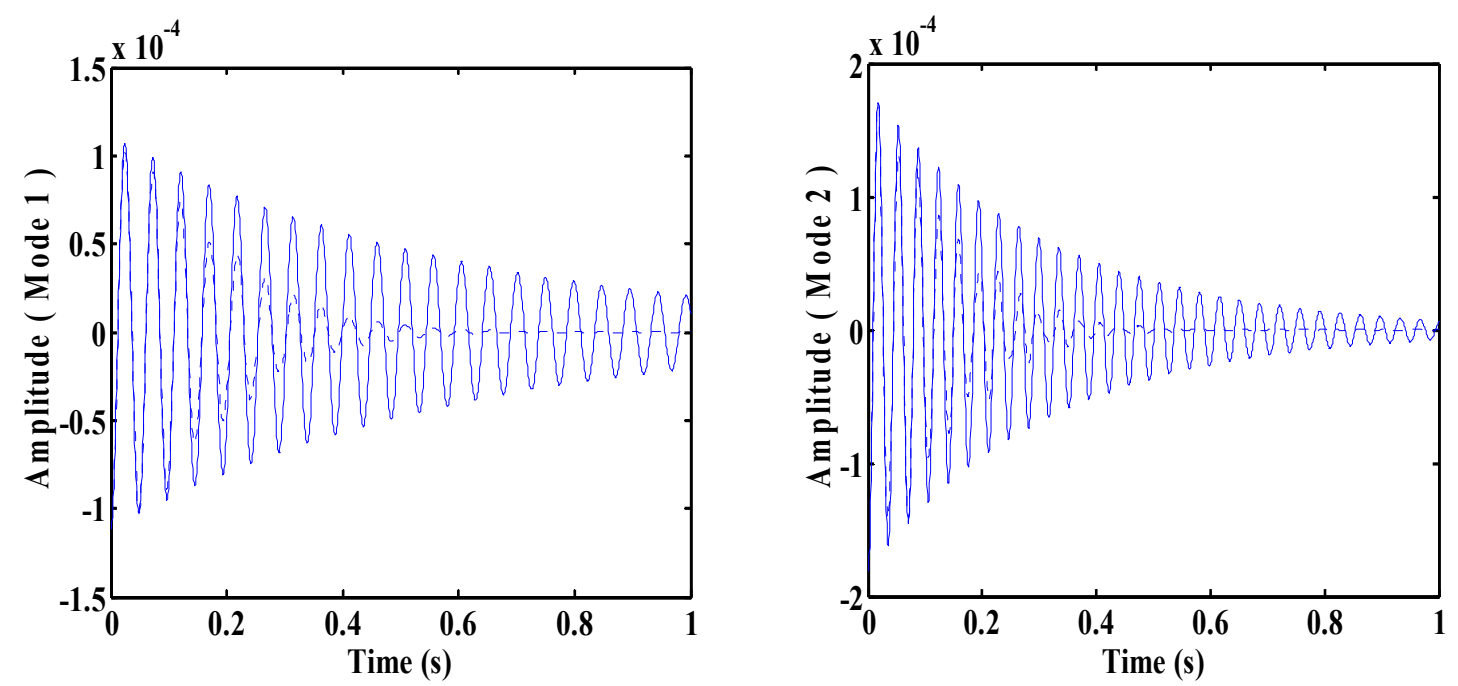

Figure 14 -- First two modal responses. --- Controlled response, _ Uncontrolled response.
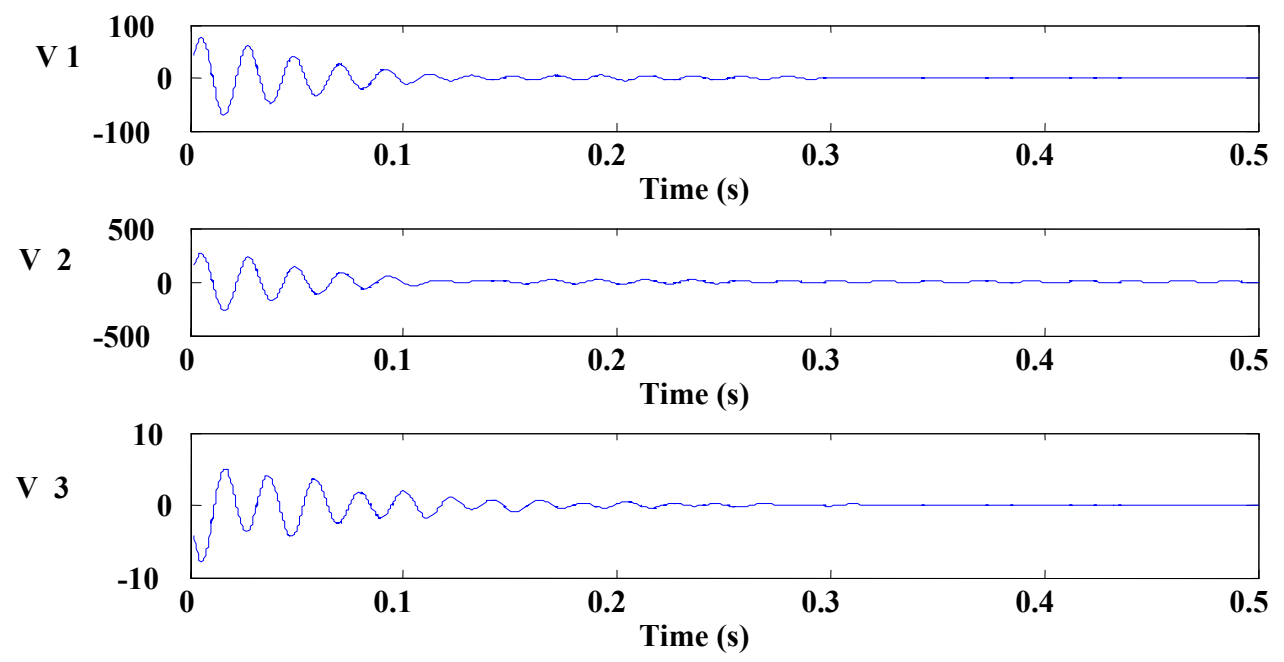

Figure 15 -- Actuator voltages for a single beam. $v_{1}$ and $v_{3}$ are the volatges in smaller vertical strips and $v_{2}$ is the voltage in the longer vertical strip (Fig. 1).

\subsection{Response to step loading}

\subsubsection{Response to sinusoidal input}

The platform is subjected at time $0.1 \mathrm{~s}$, to a sinusoidal input of $0.5 \sin \left(\omega_{1} t\right) \mathrm{N}$ at $2 \mathrm{nd}$ degree of freedom for a duration of $0.4 \mathrm{~s}$ where, $\omega_{1}$ is the first natural frequency of the 
platform. This leads to an amplification of $1.2 \times 10^{-5} \mathrm{~m}$ in the response in the uncontrolled state as shown in Fig. 16. The amplification is limited to $0.4 \times 10^{-5} \mathrm{~m}$ using an optimal control with weighing factors $\mathbf{Q}=10^{10} \mathbf{I}_{\mathrm{s}}$ and $\mathbf{R}=0.5 * \mathbf{I}_{12}$. The amplitude peak which is seen to be $1.3 \times 10^{-5} \mathrm{~m}$ at the end of $0.5 \mathrm{~s}$ does not decay to zero at the end of $2 \mathrm{~s}$ for the un-controlled state. But active control causes the same to decay to zero at $0.7 \mathrm{~s}$ which means that only $0.2 \mathrm{~s}$ are required to control the system. The voltage plots for first three actuators are given for this case in the Fig. 17 for the above values of $\mathbf{Q}$ and $\mathbf{R}$.

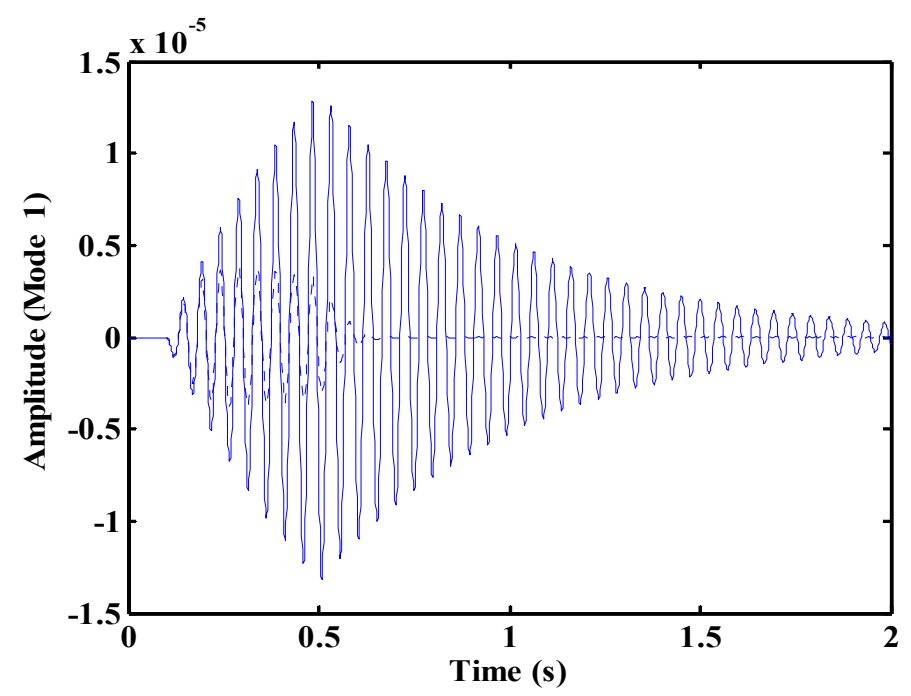

Figure 16 -- Response to sinusoidal step input.

--- Controlled response, __ Uncontrolled response. 

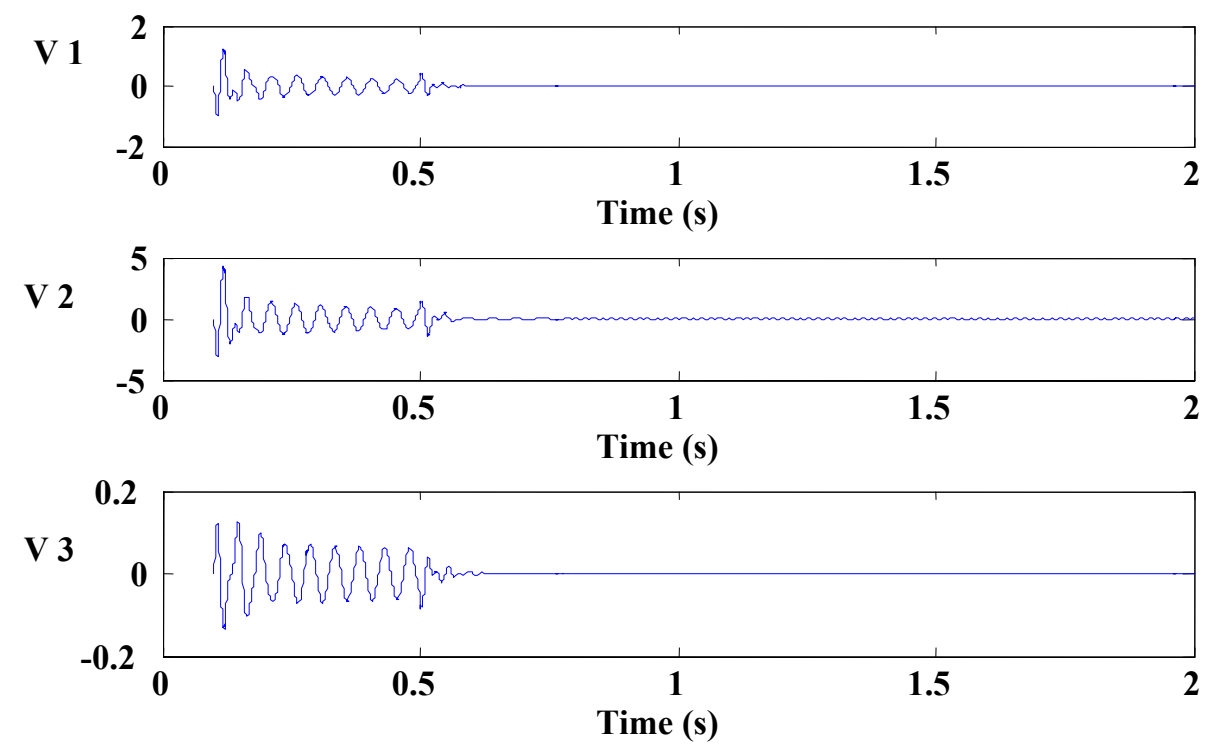

Figure 17 -- Actuator voltages for sinusoidal input for a single beam. $v_{1}$ and $v_{3}$ are the volatges in smaller vertical strips and $v_{2}$ is the voltage in the longer vertical strip (Fig. 1).

\subsubsection{Response to pulse loading}

The uncontrolled and controlled modal response of the flexible platform for a pulse load of $2 \mathrm{~N}$ applied at $2^{\text {nd }}$ degree of freedom for a duration of $0.4 \mathrm{~s}$ is simulated. The modal response contribution for this input is plotted only for the first mode and it is given in Fig. 18. It can be noted that the controlled responses are of low magnitude and the decay is very fast. When the load is taken off, the system tends to go the equilibrium and thus oscillates. It is again controlled within $0.2 \mathrm{~s}$. The LQR weighing factors are chosen as $\mathbf{Q}=10^{10}: \mathbf{I}_{8}$ and $\mathbf{R}=0.5 * \mathbf{I}_{12}$. The response peak is seen to be $1.5 \times 10^{-6} \mathrm{~m}$ at the end of $0.5 \mathrm{~s}$ and the controlled plot peak is $1 \times 10^{-6} \mathrm{~m}$. The decay is happening within $0.3 \mathrm{~s}$ for the first modal response contribution. The uncontrolled vibration lasts over $2 \mathrm{~s}$. The voltage plots for first three actuators are given for this case in the Fig. 19. The voltage again indicates that the middle vertical beam experiences higher bending strain thus producing higher control voltage. 


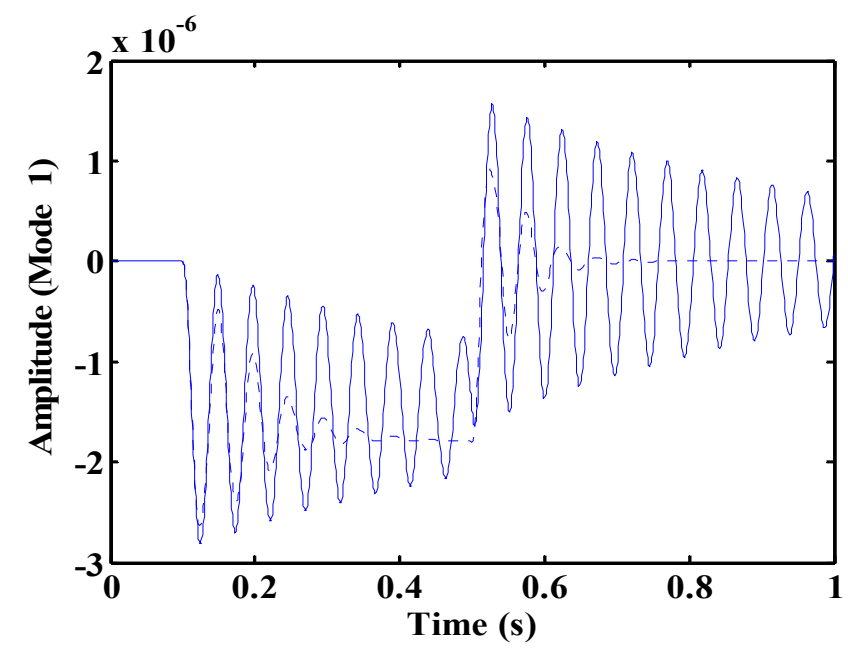

Figure 18 -- Modal response for pulse loading.

--- Controlled response, _ Uncontrolled response.
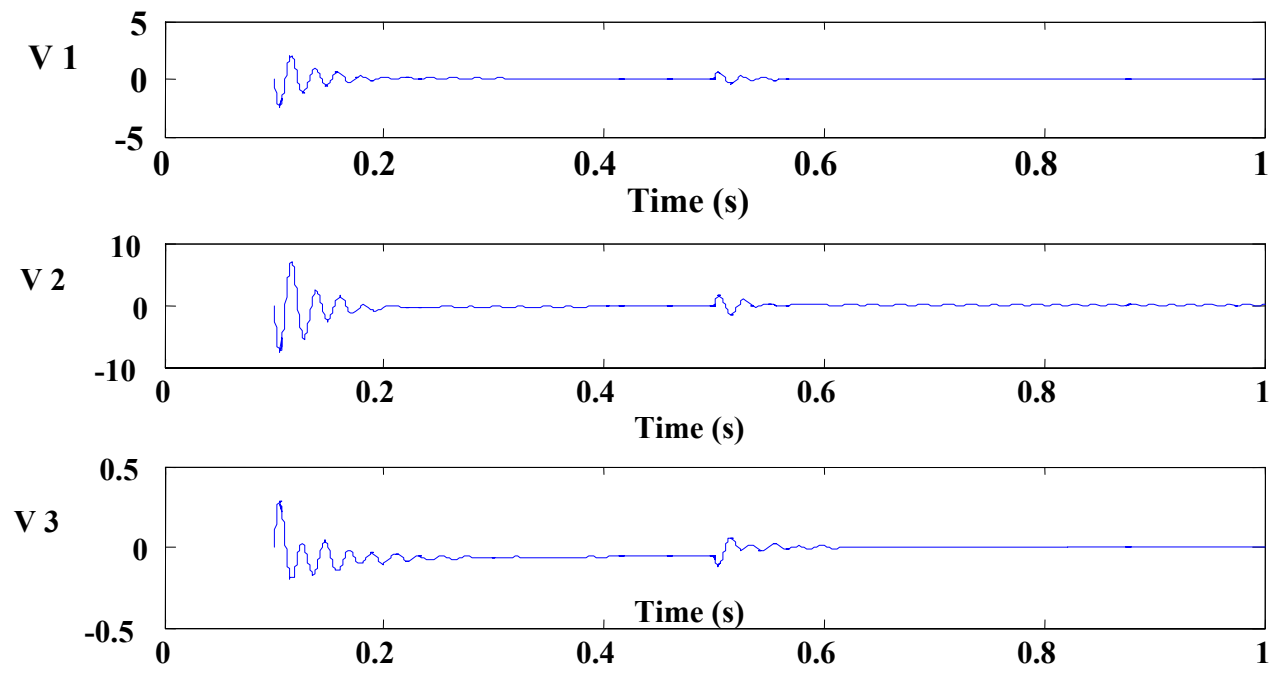

Figure 19 -- Actuator voltages for pulse input for a single beam. $v_{1}$ and $v_{3}$ are the volatges in smaller vertical strips and $\mathrm{v}_{2}$ is the voltage in the longer vertical strip (Fig. 1).

\section{Conclusion}

This paper addresses the design, modeling and analysis of low frequency space frame platform for passive and active attenuation of low amplitude vibrations. Finite element analysis of the proposed platform suggests that low frequencies can be achieved by increasing the flexibility of the platform which can be done either by decreasing the vertical beam thickness or by increasing the length of the flexible vertical beam or both. 
An increase in the number of folds also leads to low frequencies. Numerical simulations confirm that vibration isolation of disturbances on-board spacecraft could be achieved passively through this kind of platform. Active vibration control of the device, using sensors and actuators embedded as collocated pair on flexible arms, has been studied using the optimal control technique. Numerical results show that although the flexible folded beam platform is able to passively suppress the vibration for space usage, it could also be equipped with piezo-ceramic actuators and sensors to actively cut down further vibrations. Suppression of vibration has been demonstrated for harmonic loading, pulse loading and initial displacement loading conditions. In all such cases the first few modes of vibration have been effectively controlled. Therefore, we conclude that this platform configured with flexible beam structure can be used as a platform for mounting the payload where source generated vibration have to be insulated to reach out to critical location /areas of structure.

\section{References}

[1] Richard G. Cobb, Jeanne M. Sullivan, Alok Das, L. Porter Davis, T. Tupper Hyde, Torey Davis, Zahidul H. Rahman and John T. Spanos, Vibration isolation and suppression system for precision payloads in space, Smart Materials and Structure, 8, (1999), 798-812.

[2] Porter L. Davis, Delano R. Carter, Tristrem T. Hyde, Second gereration hybrid DStrut, Proc. SPIE, Vol. 2445, (1994), pp. 161-175.

[3] Joseph R. Maly, Scott C. Pendleton, J. Salmanoff, Garcia J. Blount, Kevin Mathews, Hubble Space Telescope Solar Array Damper, Proc. SPIE, Vol. 3672, (1999) pp. 186197.

[4] J. J. Rodden, H.J. Dougherty, L.F. Reschke, M.D. Hasha and L.P. Davis, Line-ofSight Performance Improvement with Reaction-Wheel Isolation, AAS Paper 86-005, Proceedings of the Annual Rocky mountain Guidance and Control conference, Keystone, CO, Feb 1-5, 1986.

[5] D. Cunningham, P. Davis and F. Schmitt, A Multi-Axis Isolation System for the French Earth Observation Satellite's Magnetic Bearing Reaction Wheel, Paper presented 
at the DPA/AIAA/ASME/SPIE Conference on Active Materials and Adaptive Structures, 1996.

[6] F. Dekens, and G. Neat, Micro-Precision Interferometer: Pointing System

Performance in On-Orbit Disturbance Environment, Proceedings of the 1999, SPIE

Smart Materials and Structures Conference, Vol. 3668, pp. 426-439.

[7] C. R. Fuller, S.J. Elliott and P.A. Nelson, Active Control of Vibration, Academic Press, 1996.

[8] Denys J. Mead, Passive Vibration Control, John Wiley and Sons, 1998.

[9] L. Porter Davis, J.F. Wilson, and R.E. Jewell, Hubble Space Telescope Reaction Wheel Assembly Vibration Isolation System, Presented at NASA Marshall Space Flight Center, Huntsville, Alabama, 1986.

[10] L. Porter Davis, Delano R. Carter and T. Tupper Hyde, Second Generation Hybrid D-Strut ${ }^{\mathrm{TM}}$, Presented at the SPIE Smart Structures and Materials Conference, San Diego, CA, 1995.

[11] E.H. Anderson, J.P. Fumo, R.S. Erwin, Satellite ultraquiet isolation technology experiment (SUITE), Aerospace Conference Proceedings, IEEE (2000) 299-313.

[12] L. Porter Davis, Dave Cunningham and John Harrell, Advanced $1.5 \mathrm{~Hz}$ Passive Viscous Isolation System, 35 AIAA SDM Conference, South Carolina, 1994.

[13] Y. C. Yiu, Regelbrugge Marc E., Shape-Memory alloy isolators for vibration suppression in space application, AIAA-95-1120-CP, (1995) 3390-3398.

[14] Mayes J. John, C. Lagoudas Dimitris and Henderson B. Kyle, An experimental investigation of shape memory alloy springs for passive vibration isolation, AIAA-20014569, pp. 321-327.

[15] Eugene I. Rivin, Passive Vibration Isolation, ASME Press, 2003.

[16] C. E. Kaplow, J. R. Velman, Active Local Vibration Isolation Applied to a Flexible Space Telescope, J. Guidance and Control, 3 (1980) 227-233.

[17] Ir. A. Abu Hanieh, and A. Preumont, Piezoelectric Stewart Platform for General Purpose Active Damping Interface and Precision Control, Proc. $9^{\text {th }}$ European Space Mechanisms \& Tribology Symposium, Liege, ESA SP-480, (2001) 331-334. 
[18] A. Preumont, M. Horodinca, I. Romanescu, B.de Marneffe, M. Avraam, A. Deraemaeker, F. Bossens, and A. Abu Hanieh, A six-axis single stage active vibration isolator based on Stewart platform, Journal of Sound and Vibration, (2007) 644-661.

[19] Nader Jalili and David W Knowles IV, Structural vibration control using an active resonator absorber: Modelling and Control implementation, Smart Materials and structures 13 (2004) 998-1005.

[20] L. Vaillon and C. Philippe, Passive and active vibration microvibration control for very high pointing accuracy space system, Smart Materials and Structure, 8 (1999) 719728.

[21] Edward F. Crawley and Javier de Luis, Use of piezoelectric actuators as elements of intelligent structures, AIAA Journal, 25 (1987) 1373-1385.

[22] Thomas Bailey and James E. Hubbard Jr., Distributed piezoelectric polymer active vibration control of a cantilever beam, Journal of Guidance, Dynamics and Control, 8 (5) (1985) 605-611.

[23] S. Hanagud, M.W. Obal, and A.J. Callise, Optimal vibration control by the use of piezosensors and actuators, Journal of Guidance, Control, and Dynamics, 15 (5) (1992) 1199-1206.

[24] S. Narayanan and V. Balamurugan, Finite element modelling of piezolaminated smart structures for active vibration control with distributed sensors and actuators, Journal of Sound and Vibration, 262 (2003) 529-562.

[25] CARTOSAT-2 project, Preliminary design review document on IRU and high torque reaction wheel, ISRO IISU (125) 2002.

[26] Stephen J. Chapma, Matlab Programming for Engineers, Second Edition, Thomson Books Cole, 2004.

[27] William Weaver, Jr, Paul R. Johnston, Structural Dynamics by Finite elements, Prentice Hall, Inc., Eaglewood Cliffs, New Jersey, 1987.

[28] Andre Preumont, Vibration Control of Active Structures, An Introduction, 2nd Edition, Kluwer Academic Publishers, 2002.

[29] George A Lesieutre, Usik Lee, A finite element for beams having segmented active constrained layers with frequency-dependent viscoelastic material properties, SPIE 3045, pp. $315-328$. 
[30] T. C. Manjunath, B. Bandyopadhyay, Control of Vibration in Flexible Smart Structures using Fast Output Sampling Feedback Technique, International Journal of Computational Intelligence, 3 (1) (2006) 1304-2386. 